\title{
Three-dimensional analysis of nuclear heterochromatin distribution during early development in the rabbit
}

\author{
Amélie Bonnet-Garnier ${ }^{1}$ (D) $\cdot$ Kiên Kiêu ${ }^{2}$. Tiphaine Aguirre-Lavin ${ }^{1} \cdot$ Krisztina Tar $^{3,4}$ • Pierre Flores ${ }^{1} \cdot$ Zichuan Liu $^{1,5,6}$. \\ Nathalie Peynot ${ }^{1}$ - Martine Chebrout ${ }^{1}$ • András Dinnyés ${ }^{4}$ - Véronique Duranthon ${ }^{1}$ • Nathalie Beaujean ${ }^{1,7}$
}

Received: 12 October 2017 / Revised: 6 March 2018 / Accepted: 3 April 2018 / Published online: 18 April 2018

(C) The Author(s) 2018

\begin{abstract}
Changes to the spatial organization of specific chromatin domains such as constitutive heterochromatin have been studied extensively in somatic cells. During early embryonic development, drastic epigenetic reprogramming of both the maternal and paternal genomes, followed by chromatin remodeling at the time of embryonic genome activation (EGA), have been observed in the mouse. Very few studies have been performed in other mammalian species (human, bovine, or rabbit) and the data are far from complete. During this work, we studied the three-dimensional organization of pericentromeric regions during the preimplantation period in the rabbit using specific techniques (3D-FISH) and tools (semi-automated image analysis). We observed that the pericentromeric regions (identified with specific probes for Rsat I and Rsat II genomic sequences) changed their shapes (from pearl necklaces to clusters), their nuclear localizations (from central to peripheral), as from the 4-cell stage. This reorganization goes along with histone modification changes and reduced amount of interactions with nucleolar precursor body surface. Altogether, our results suggest that the 4-cell stage may be a crucial window for events necessary before major EGA, which occurs during the 8 -cell stage in the rabbit.
\end{abstract}

Keywords Embryos $\cdot 3$ D-FISH $\cdot$ Centromeres $\cdot$ Epigenetic modifications $\cdot$ Satellite sequences

\section{Abbreviations}

3D

BSA

CENPs
Three-dimensional

Bovine serum albumin

Centromeric proteins $\mathrm{A} / \mathrm{B}$
DAPI

EGA

EVF

FISH
4',6-Diamidino-2-phenylindole

Embryonic genome activation

Eroded volume fraction

Fluorescent in situ hybridization

This paper is dedicated to the memory of Kiên Kiêu, our colleague gone too soon.

Electronic supplementary material The online version of this article (https://doi.org/10.1007/s00412-018-0671-z) contains supplementary material, which is available to authorized users.

Amélie Bonnet-Garnier

amelie.bonnet-garnier@inra.fr; http://www6.jouy.inra.fr/bdr

Krisztina Tar

tark@med.unideb.hu

Zichuan Liu

zichuan.liu@fmi.ch

1 UMR BDR, INRA, ENVA, Université Paris Saclay, 78350 Jouy-en-Josas, France

2 UR341 MaIAGE, INRA, Université Paris Saclay, 78350 Jouy-en-Josas, France
3 Present address: Department of Medical Chemistry, Faculty of Medicine, University of Debrecen, Debrecen, Hungary

4 BioTalentum Ltd., Aulich Lajos str. 26, Gödöllő 2100, Hungary

5 Present address: Friedrich Miescher Institute for Biomedical Research, Basel, Switzerland

6 State Key Laboratory of Reproductive Biology, Institute of Zoology, Chinese Academy of Sciences, Beijing 100101, China

7 Present address: Univ Lyon, Université Claude Bernard Lyon 1, Inserm, INRA, Stem Cell and Brain Research Institute U1208, USC1361, 69500 Bron, France 


$\begin{array}{ll}\text { FITC } & \text { Fluorescein isothiocyanate } \\ \text { H3K9me3 } & \text { Histone-3 tri-methylated in lysine 9 } \\ \text { H4K20me3 } & \text { Histone-4 tri-methylated in lysine 20 } \\ \text { HP1 } & \text { Heterochromatin protein 1 } \\ \text { NPB } & \text { Nucleolar precursor body } \\ \text { PBS } & \text { Phosphate-buffered saline } \\ \text { PFA } & \text { Paraformaldehyde } \\ \text { mPN } & \text { Male pronucleus } \\ \text { fPN } & \text { Female pronucleus } \\ \text { RT } & \text { Room temperature } \\ \text { Rsat } & \text { Rabbit satellite sequences } \\ \text { SSC } & \text { Saline sodium citrate buffer }\end{array}$

\section{Introduction}

The nucleus of a cell is divided into several membrane-less compartments such as the nucleolus or nuclear speckle (Dundr 2012) that are dedicated to specific nuclear functions (rRNA expression and processing or RNA splicing) (Dundr and Misteli 2010; Sawyer et al. 2016). During the past 10 years, the involvement of nuclear architecture in the regulation of gene expression, and more particularly the spatial organization of chromatin, have been studied intensively (for a review, see Schneider and Grosschedl 2007; Joffe et al. 2010; Bickmore and van Steensel 2013; Pombo and Dillon 2015; Dekker and Heard 2015).

Especially, the genome is organized in chromosomes that occupy specific chromosome territories (CTs) in the interphase nucleus. In somatic cells, these $\mathrm{CTs}$ are not arranged at random (Cremer and Cremer 2010), and it is generally accepted that gene-poor chromosomes are located at the periphery of the nucleus while their gene-rich counterparts are found in the center (Croft et al. 1999; Boyle et al. 2001; Hübner and Spector 2010). In addition, some specific genomic regions (such as gene clusters) tend to change their threedimensional (3D) position in correlation with their transcription status (Lanctot et al. 2007; Therizols et al. 2014) and may even loop out of the CTs (Volpi et al. 2000; Chambeyron and Bickmore 2004).

The interphase chromatin comprises open regions that permit transcription (the euchromatin) or dense and compact regions that allow little or no transcription (the heterochromatin) (Zinner et al. 2006; Joffe et al. 2010; Politz et al. 2013). In somatic or embryonic stem cells, heterochromatin is principally located at the nuclear envelope or around the nucleolus and generally corresponds to telomeric, centromeric, and pericentromeric regions. In numerous species (human, mouse, chicken, bovine), the centromeric and pericentromeric heterochromatin of several chromosomes cluster to form specific structures called chromocenters (Haaf and Schmid 1991; Guenatri et al. 2004; Maslova et al. 2015). These highly condensed pericentromeric regions, intensely labeled with 4',6- diamidino-2-phenylindole (DAPI) dye, are mostly composed of A-T-rich DNA sequences (called major and minor satellites in the mouse; Vissel and Choo 1989; Lehnertz et al. 2003) and are associated with repressive histone marks: such as histone H4 trimethyl Lys20 (H4K20me3) and histone H3 trimethyl Lys9 (H3K9me3) which attracts the heterochromatinspecific protein HP1 through its chromodomain (Peters et al. 2001, 2003; Maison and Almouzni 2004). Similarly, centromeric regions are characterized by specific centromeric proteins (CENPs) (Cheutin et al. 2003).

Changes to the spatial organization of these chromatin compartments (chromosome, gene clusters, or heterochromatin) have been observed during differentiation (Solovei et al. 2009) or senescence (Chandra and Narita 2013), but most work to date has been performed in somatic cells. Indeed, only a few studies have been carried out in the context of early development on bovine or rabbit embryos (Koehler et al. 2009; Pichugin et al. 2010; Yang et al. 2013; Popken et al. 2014a, b; review in Borsos and Torres-Padilla 2016).

Early embryonic development in mammals, from fertilization to implantation, is a particularly critical period. The newly formed zygote needs to remodel the highly specialized parental chromatin and switch on its own transcription within a very short time frame (Schultz et al. 1999), an event referred to as embryonic genome activation (EGA) which occurs at different points depending on the species (review in Schultz and Heyner 1992; Telford et al. 1990): at the 2-cell stage in the mouse (Moore 1975; review in Schultz 1993), at the 4- to 8cell stages in humans (Braude et al. 1988), at the 8-cell stage in the bovine (Camous et al. 1984, 1986; Memili and First 1998; Graf et al. 2014), and between 8- and 16-cell stages in the rabbit (Manes 1973; Brunet-Simon et al. 2001).

This preimplantation period (from zygote to blastocyst) is characterized by major changes: epigenetic reprogramming, the onset of transcription, transition from a totipotent to a pluriporent state, and initial differentiations. A body of evidence has shown that these processes are accompanied by a drastic reorganization of nuclear architecture. Indeed, several studies on early embryonic development in the mouse (Martin et al. 2006a, b; Probst et al. 2007; Aguirre-Lavin et al. 2012) have demonstrated that the pericentromeric heterochromatin organization is dramatically modified during EGA and that these changes are essential for the embryo to fully develop to term (Maalouf et al. 2009; Probst et al. 2010). Moreover, specific structures called NPBs (nucleolar precursor bodies) appear to play an important role (review by Fulka and Aoki 2016). Firstly, at the 1-cell stage, several teams have suggested that NPBs ensure the correct remodeling of heterochromatin regions composed of "major satellite" sequences (Ogushi and Saitou 2010; Jachowicz et al. 2013; Fulka and Langerova 2014; Kyogoku et al. 2014). Secondly, these NPBs serve as a platform for the development of functional nucleoli from the end of the 2-cell stage through the morula stage (Zatsepina 
et al. 2003; Lavrentyeva et al. 2015; Koné et al. 2016). In the mouse, the removal of nucleolus-like structures from the growing oocyte, or the removal of NPBs at the start of the 1cell stage, can lead to an arrest of development at the 2-cell stage. In addition, the organization of centromeric and pericentromeric sequences is disturbed and they display architectural defects (Fulka and Langerova 2014; Kyogoku et al. 2014).

In rabbit, Baran et al. (1997) identified by electron microscopy NPBs as round shape and compact structures from the 1to 8-cell stages. At the 16-cell stage, some NPBs (called ANPB) displayed a less compact structure associated with RNA detection but fully functional nucleoli were only detected at the morula and blastocyst stages (Baran et al. 1997). However, very few information are available concerning the nuclear organization in 3D (Yang et al. 2013; Popken et al. 2016) and the epigenetic marks associated with pericentromeric heterrochromatin (Brero et al. 2009; Reis e Silva et al. 2011; Salvaing et al. 2016) during early embryonic development in rabbit. In our previous study of heterochromatin organization (Yang et al. 2013), the HP1 $\beta$ and CENP patterns observed using immunodetection were seen to change at the time of EGA (8-cell stage).

However, chromocenters were not easily detected with these two proteins, so we decided to complete our study using probes specific to pericentromeric sequences during early embryonic development in the rabbit. We then examined the organization of constitutive heterochromatin in relation to EGA. Unlike the mouse, the remodeling of maternal and paternal genomes that occurs during the two first cell cycles after fertilization (Fulka et al. 2008) can be distinguished from the EGA at the 8-cell stage, making the rabbit an interesting model. We took advantage of the identification of two families of DNA repeat sequences (named Rsat I and Rsat II) which both localize to pericentromeric regions (Ékes et al. 2004). The Rsat I sequence comprises 375-bp-long repeat units while Rsat II is composed of repeat units between 585 and $590 \mathrm{bp}$ (Ékes et al. 2004). Rsat I and Rsat II hybridized to the pericentromeric/centromeric regions of 11 and 12 different chromosomes pairs, respectively, and had nine chromosome pairs in common. To investigate the spatial distribution of pericentromeric/centromeric heterochromatin, we studied the three-dimensional distribution of Rsat I/Rsat II sequences in the nucleus using the fluorescent in situ hybridization (3DFISH) technique over the course of preimplantation development on whole-mount rabbit embryos (protocol adapted from that described by Aguirre-Lavin et al. 2012). We therefore used a semi-automated approach developed previously by our team (Ballester et al. 2008; Andrey et al. 2010) to investigate the morphometric features of pericentromeric/ centromeric heterochromatin and determine their spatial distribution in the nucleus from confocal image stacks. We also studied their localization relative to the NPBs and determined the distribution of two epigenetic marks (H3K9me3 and H4K20me3) which classically characterize pericentromeric heterochromatin.

\section{Material and methods}

\section{Ethics}

Animal care and handling were carried out according to European regulations on animal welfare. $\mathrm{ABG}, \mathrm{NB}$, and $\mathrm{VD}$ are authorized to work with laboratory animals by Departmental Veterinary Regulatory Services (Nos. 78-184, 78-95, and, 78-101, respectively). This work was approved by the local Ethics Committee (Comethea Jouy-en-Josas/ AgroParisTech accreditations 12/107 and 15-59 for in vitro analyses).

\section{Recovery of rabbit embryos and culture}

Embryos were obtained from mature female New Zealand white rabbits after in vivo fertilization. Superovulation in the female rabbits was induced by five subcutaneous injections of pFSH (Stimufol ${ }^{\circledR}$, Merial, France) during the 3 days prior to mating (two $5-\mu \mathrm{g}$ doses on the first day at 12-h intervals, two $10-\mu \mathrm{g}$ doses on the second day at $12-\mathrm{h}$ intervals, and one $5-\mu \mathrm{g}$ dose on the third day), followed $12 \mathrm{~h}$ later by an intravenous administration of 30 IU HCG (Chorulon, MSD Animal Health, USA) at the time of natural mating with male New Zealand white rabbits (Reis e Silva et al. 2011; Salvaing et al. 2016). The zygotes were flushed from the oviducts with PBS at $19 \mathrm{~h}$ post-coitum (hpc) and cultured in vitro up to different stages in M199 (Sigma-Aldrich, USA) supplemented with $2.5 \%$ fetal calf serum under mineral oil (Sigma-Aldrich, USA) in an incubator at $38.5{ }^{\circ} \mathrm{C}$ under $5 \% \mathrm{CO}_{2}$ in air. The embryos were fixed and processed at 19 or $22 \mathrm{hpc}$ (1-cell stage), $27 \mathrm{hpc}$ (2-cell stage), $34 \mathrm{hpc}$ (4-cell stage), $42 \mathrm{hpc}$ (early 8-cell stage), $45 \mathrm{hpc}$ (mid 8-cell stage), $48 \mathrm{hpc}$ (late 8cell stage), and $58 \mathrm{hpc}$ (16-cell stage). All the embryos were then incubated in $5 \mathrm{mg} / \mathrm{ml}$ Pronase (Sigma-Aldrich, USA) at $37{ }^{\circ} \mathrm{C}$ for 5 to $10 \mathrm{~min}$ and transferred to HEPES medium (Sigma-Aldrich, USA) at $37^{\circ} \mathrm{C}$; then, mechanic removal of the zona pellucida was achieved by successive passages through a very fine pipette.

\section{Antibodies}

HP1 $\beta$ was detected with a mouse monoclonal antibody (clone 1 MOD 1A9, Euromedex, 1:250 diluted in 2\% bovine serum albumin (BSA) in PBS), using a rhodamine (TRITC)-conjugated anti-mouse secondary antibody (\#715-025-151, Jackson ImmunoResearch, USA). The centromeres were labeled with a human CREST antibody which mostly 
recognizes CENP-A (Immunovision, Cellon Sarl, 1:250 in 2\% BSA/PBS), using FITC-conjugated anti-human secondary antibody (\#709-095-149, Jackson ImmunoResearch, USA). H3K9me3 and H4K20me3 were detected with rabbit polyclonal antibodies (39161 from Active Motif and ab9053 from Abcam, diluted $1: 500$ in 2\% BAS/PBS) using a Cy5conjugated anti-rabbit secondary antibody (\#711-175-152, Jackson ImmunoResearch, USA). All the Jackson ImmunoResearch secondary antibodies raised in donkey were used at a dilution of 1:200 in 2\% BSA/PBS.

\section{Immunofluorescence staining}

The embryos thus harvested were processed for HP $1 \beta$ and CENPs, H3K9me3, or H4K20me3 immunostaining, as previously described (Pichugin et al. 2010; Yang et al. 2013). Briefly, the embryos were fixed in $2 \%$ paraformaldehyde (PAF; Sigma-Aldrich, USA) in PBS at RT for $20 \mathrm{~min}$ and permeabilized with $0.5 \%$ Triton X-100 (Sigma-Aldrich, USA) in PBS for $30 \mathrm{~min}$ on a heating plate at $25^{\circ} \mathrm{C}$. They were then blocked for $1 \mathrm{~h}$ at RT with $2 \% \mathrm{BSA} / \mathrm{PBS}$ and incubated with the primary antibodies overnight at $4{ }^{\circ} \mathrm{C}$. After three washes with $0.05 \%$ Tween-20 (Sigma-Aldrich, USA) in PBS (15 min each), the embryos were incubated with the secondary antibodies $(1 \mathrm{~h}, \mathrm{RT})$ then washed again and postfixed for 10 min using 2\% PFA. If any histone modifications were detected, DNA was counterstained with DAPI (Invitrogen) at $10 \mu \mathrm{g} / \mathrm{ml}$. For microscopic observations, the embryos were mounted onto glass slides in Vectashield antifading agent (Vector Laboratories, USA).

\section{D-FISH experiments}

FISH experiments were performed using DNA probes specific to the Rsat I and Rsat II sequences (Ékes et al. 2004) according to our standard protocol (Maalouf et al. 2009; Aguirre-Lavin et al. 2012) on 3D-preserved embryos.

The Rsat I and Rsat II probes were amplified by PCR on genomic rabbit DNA with the following primers: 5' GAACAGGAAGATTGTGGTT 3' and 5' ATGTGTGG AGGATTTGA CTC 3' (Rsat I) and 5' ACTCAGAC CCAGAAAACATTA $3^{\prime}$ and 5' CTTAGAAATCTA CAGGTAACACGAC 3' (Rsat II) according to the method described by Ékes et al. (2004). They were then labeled with Cy3 (Rsat I) or Cy5 (Rsat II) by random labeling (Invitrogen Kit, ref. 18095-011).

Unless otherwise specified, all steps were performed at room temperature (RT). After removal of the zona pellucida, the embryos were rinsed in HEPES medium (Sigma-Aldrich, USA), fixed in 4\% PFA for 30 min, rinsed in PBS, and gently deposited with a minimum amount of PBS on a microscope slide to enable adherence (Menzel Superfrost Plus, Thermo Scientific). They were then fixed again in $4 \%$ PFA for
$30 \mathrm{~min}$, permeabilized for $30 \mathrm{~min}$ in $0.5 \%$ Triton $\mathrm{X}-100$, and rinsed once for $5 \mathrm{~min}$ in $2 \times$ saline-sodium citrate $(2 \times \mathrm{SSC}) \mathrm{pH}$ 6.3. RNA digestion was performed by incubation in $200 \mu \mathrm{g} / \mathrm{ml} \mathrm{RNase}$ (Sigma, USA) in $2 \times$ SSC for $30 \mathrm{~min}$ at $37^{\circ} \mathrm{C}$. After two rinses in $2 \times \mathrm{SSC}(5 \mathrm{~min}$ each) at room temperature, the slide was equilibrated in a hybridization buffer $(50 \%$ formamide, SCC $2 \times$, Denhardt $1 \times, 40 \mathrm{mM}$ $\mathrm{NaH}_{2} \mathrm{PO}_{4}, 10 \%$ dextran sulfate) for 1 to $2 \mathrm{~h}$. The probe mix $(1 \mu$ l Cy3-Rsat I solution $(145 \mathrm{ng} / \mu \mathrm{l}), 2 \mu \mathrm{l}$ Cy5 Rsat II solution $(87 \mathrm{ng} / \mu \mathrm{l})$ completed to $20 \mu \mathrm{l}$ with hybridization buffer) and the slide were denatured separately for 10 min at $85^{\circ} \mathrm{C}$. A drop of hybridization mix containing the probes was then deposited on the slide, which was placed for $24 \mathrm{~h}$ at $37{ }^{\circ} \mathrm{C}$ in a humidified chamber. The samples were rinsed twice with $2 \times \mathrm{SSC}$ at $42{ }^{\circ} \mathrm{C}$ and postfixed in 2\% PFA for 15 min. DNA was counterstained with YoproI (Molecular Probes, $1 \mu \mathrm{M}$ ), and Vectashield (Vector Laboratories, USA) was used as the mounting medium.

\section{Fluorescence microscopy}

The embryos were examined with a ZEISS LSM 510 or 700 confocal laser scanning microscope (MIMA2 Platform, INRA). Observations were made using a $63 \times$ oil-immersion objective (NA 1.4). $Z$ stacks were acquired with a frame size of $512 \times 512$ or $1024 \times 1024$, a pixel depth of 8 bits, and a $z$ distance of $0.37 \mu \mathrm{m}$ between optical sections. Fluorescence wavelengths of $405,488,555$, and $639 \mathrm{~nm}$ were used to excite DAPI, YoProI or Alexa-488, Cy3, and Cy5, respectively.

\section{Image and statistical analyses}

All embryos were analyzed visually with LSM510 or Zen software (Zeiss), step-by-step through the confocal $z$ stacks and with the help of 3D reconstructions using AMIRA software. Except for the 1-cell stage embryos, which displayed a peculiar nuclear organization, we analyzed all the preimplantation embryos using the semi-automated image processing and analytical tools described below.

Three-dimensional images of nuclei acquired with the LSM510 software and saved as lsm files were processed using the ITK library (Yoo et al. 2002) and its Python interface (Lehmann et al. 2006).

Nuclear volumes were segmented for both CENP and Rsat images. Rsat spots were segmented in Rsat images. The HP1ß signal was smoothed before thresholding using several standard filters (median, Gaussian, opening/closing, gray hole filling). Thresholds for CENP images were determined using the RATS method (Kittler et al. 1985). As for Rsat images, thresholds were computed using the maximum entropy or Otsu method. Post-processing was performed in order to remove any masks that were too small or over-truncated (by the image 
boundary). Merged masks in CENP images were separated by applying a watershed transform on distance maps.

In order to quantify the radial position of non-segmented signals, a variant of the eroded volume fraction (EVF) was derived from the work by Ballester et al. (2008). In the original method, the EVF of a point within a nucleus is defined as the fraction of nuclear volume lying between that point and the nuclear membrane. The EVF rises from 0 for a signal at the nuclear periphery to 1 for a signal at the nuclear center. The EVF of points uniformly distributed within a nucleus is uniformly distributed between 0 and 1 , and this property holds for any shape of the nucleus. In our study, we divided the nucleus into fractions with identical volumes, such that the mean EVF in each fraction increased linearly as the fractions were closer to the nuclear center and farther from the nuclear periphery. Then, for each fraction, we determined the proportion of the respective Rsat signals relative to the total signal in the nucleus, and compared the cumulative distribution obtained with the ideal case where the signal was uniformly distributed within the nucleus. In that case, the EVF distribution was exactly the identity function on the $[0,1]$ interval, with 0 referring to the nuclear periphery. For each nucleus, the deviation from the uniform distribution was measured by the largest signed difference $d_{\max }$ between the two distributions for all the fractions. $d_{\max }$ values were between -1 and 1 , with positive values indicating a bias towards a more peripheral signal, and negative values a more central one. The higher the absolute $d_{\max }$ value is, the stronger the distribution bias is. The EVF method was obtained from the ITK library using 1000 fractions, and the results were analyzed using $\mathrm{R}$.

Rsat spot segmentation started with a de-noising stage based on a Gaussian filter and a white tophat filter on volumes (high-pass filtering). Segmentation was performed using a standard white tophat filter, the height being defined as a quarter of the maximum intensity of the Rsat signal within the nuclear mask. Post-processing was applied to remove segmented spots below a size threshold so that no account would be taken of any false positives.

Assessing the polarity of Rsat spots (after segmentation) was based on the distance between the nuclear centroid and the centroid of all Rsat spots. Because this measurement depended on the size and shape of the nucleus, we applied the shape normalization method implemented in the ITK library. For each nucleus, we compared the distance between centroids measured to a uniform distribution of distances, these being were generated by simulation (500 random patterns of spots simulated per nucleus). A one-sample $t$ test was performed between the distance measured and the simulated data, and the resulting $p$ value was computed. The distribution of the $p$ values obtained for the Rsat I signal were compared at each cell stage. A uniform distribution of $p$ values (between 0 and 1) should indicate a random distribution of the spots in the nucleus. Small $p$ values indicate great distances between nucleus and spot centroids and allow us to conclude to a polarity of the spots. $P$ values close to 1 indicate small distances between centroids corresponding to a central position of the spots.

All statistical analyses and tests were performed using the associated R packages (R Development Core Team 2008). The normality and homogeneity of variances were tested using the "shapiro.test" and "bartlett.test" R packages, respectively, and linear models ("lm" or "glm" packages) with one fixed factor (stage) and one covariate were used to perform variance analysis throughout the period of development.

\section{Results}

\section{Distribution and organization of Rsat I/Rsat II sequences in somatic cells}

We first tested Rsat I/Rsat II labeled with two different dyes (Cy3 and Cy5, respectively) and performed dual-color FISH on rabbit fibroblasts, either on metaphase spreads or on interphase 3D-preserved nuclei (Fig. 1a and Fig. S1a). We observed that in metaphase $(2 n=44)$ of rabbit fibroblasts (Fig. 1a), 11 chromosome pairs were labeled with Rsat I, one of these pairs having spots on both side of the centromere and the other chromosome pairs only displaying spots on one side. Six chromosome pairs were labeled with Rsat II: four pairs exhibited very strong signals and two pairs had weaker signals. In total, we detected 24 Rsat I and 12 Rsat II spots (Fig. 1a). Seven autosome pairs and the sexual chromosomes were not labeled with the probes used, similar to the findings of Ékes et al. (2004), and three chromosome pairs were labeled with both Rsat I and Rsat II sequences (arrowhead in Fig. 1a). During the interphase nucleus of a rabbit fibroblast, the sequences were clustered and mostly observed (Fig. S1a) at the nuclear periphery near the envelope.

\section{Nuclear organization and dynamics of Rsat I/Rsat II sequences in 1-cell through 16-cell stage embryos}

To determine whether Rsat I and Rsat II sequences are reorganized during EGA, we performed 3D-FISH experiments on whole-mount rabbit embryos from fertilization through the 16-cell stage (Fig. 1b). In all FISH experiments on rabbit embryos, particular attention was paid to preserving the three dimensions of the nucleus, as illustrated in Fig. S1b. At the 1-cell (zygotic) stage we observed that Rsat I and Rsat II sequences are highly decondensed and formed pearl necklace-like structures that partially surround nucleolar precursor bodies (NPBs), in both male and female pronuclei ( $\mathrm{mPN}$ and $\mathrm{fPN}$ ). Moreover, Rsat II sequences appear even more decondensed than Rsat I sequences at this 


\section{a}
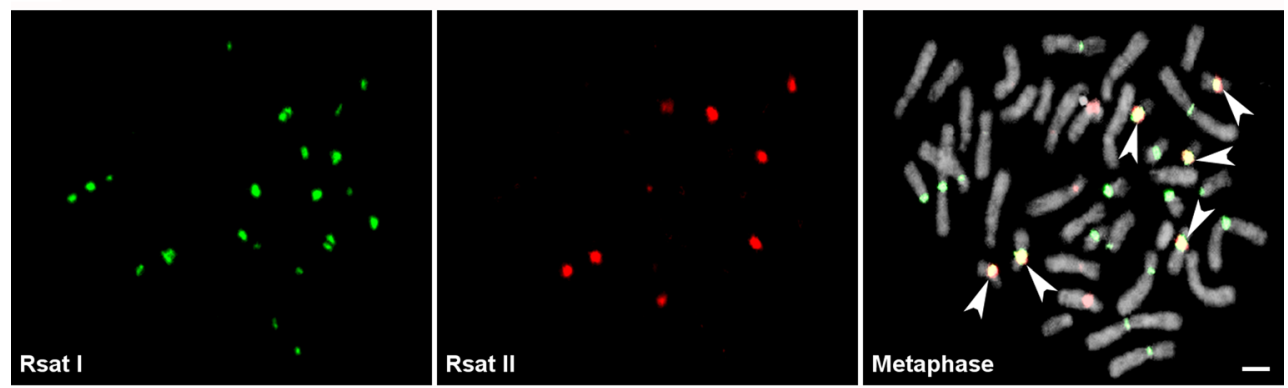

b
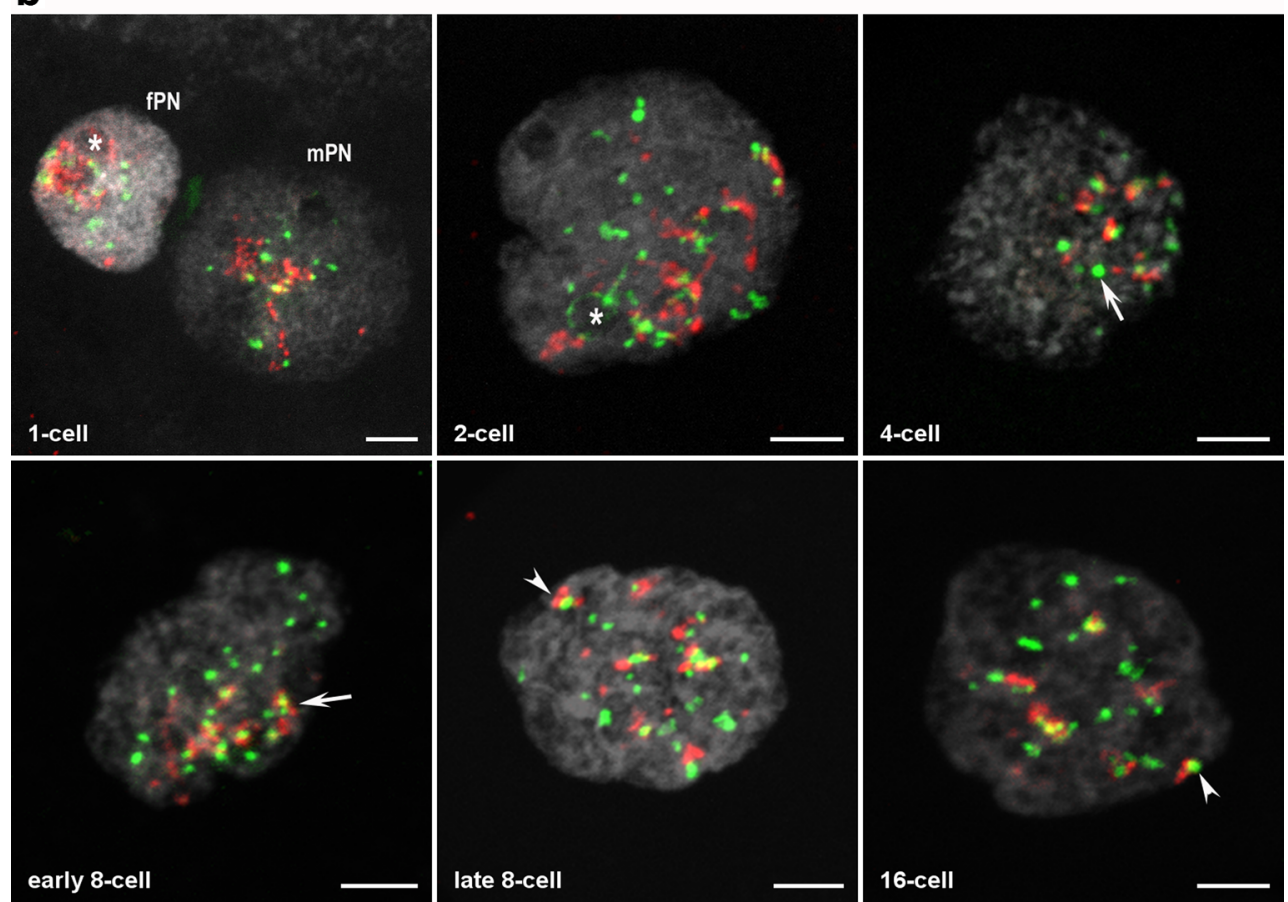

Fig. 1 Localization of Rsat I/Rsat II DNA FISH signals on metaphase (a) and at different stages of rabbit preimplatation development (b). 2D or 3D-FISH were performed using specific probes against Rsat I (green) and Rsat II (red) sequences. DNA was counterstained with DAPI or Yopro-1 (gray). a Distribution of Rsat I/Rsat II FISH signals on the chromosome spread. The FISH signals of 24 Rsat I spots and 12 Rsat II spots were observed in the centromeric and pericentromeric regions of 12 chromosome pairs. Arrowheads indicate chromosomes labeled with both Rsat signals. Scale bar $=1 \mu \mathrm{m}$. $\mathbf{b} Z$ maximal projection of representative images of a nucleus from embryos fixed at the 1 -cell stage $(19 \mathrm{~h}$ post-coitum $(\mathrm{hpc})$ ) with female and male pronuclei (fPN and $\mathrm{mPN}$ ), and the 2-cell $(24 \mathrm{hpc}), 4$-cell $(34 \mathrm{hpc})$, early and late 8 -cell (42 and $49 \mathrm{hpc}$, respectively), and 16-cell $(58 \mathrm{hpc})$ stages. Asterisks indicate NPBs associated with Rsat I/Rsat II FISH signals. Arrow and arrowheads indicate foci of Rsat FISH signals that are aggregated. Scale bar $=5 \mu \mathrm{m}$. Images were adjusted for brightness/contrast settings in each individual channels using ImageJ stage (arrow in Fig. S1c). This could be explained by the fact that Rsat II locus contains more tandem repeats than Rsat I. This pattern of continuous or partial rings around the NPBs was also observed in 2-cell stage embryos (asterisk in Fig. 1b and arrow in Fig. S1c), although the sequences were less decondensed than in pronuclei. At the 4-cell and early 8-cell stages, the Rsat I and II sequences started to cluster together (arrows in Fig. 1b) and were located in one part of the nuclei (Fig. S2) but were still associated with some NPBs (arrow Fig. S1c). From the 8- to 16cell stages, the Rsat I and II sequences formed larger foci (arrowheads in Fig. 1b) which appeared to be distributed at random within the nuclei (Fig. 1b, lower panel). Still, some foci are found at the surface of some NPBs (arrow Fig. S1c).

To further investigate the spatial and temporal distribution of these sequences, we defined four parameters to characterize the Rsat signal pattern (Fig. 2). These parameters were as follows: (1) Rsat I or II sequences forming pearl necklacelike structures (named "necklace"; fine arrow in Fig. 2a), (2) Rsat I or II sequences forming aggregates (named "aggregate"; arrow in Fig. 2b), (3) Rsat I or II sequences located at the periphery of the NPBs (highlighted by an asterisk in Fig. 2a, b or an arrow in Fig. S1c), and (4) Rsat I or II sequences located at the periphery of the nuclear 

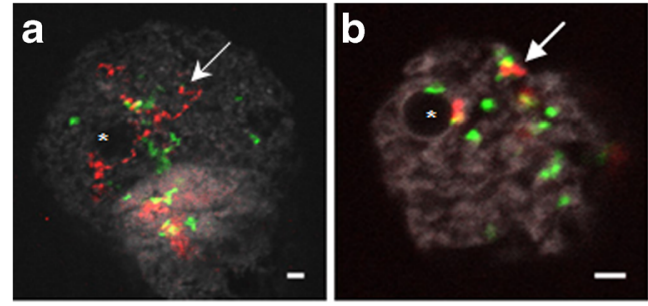

Necklace

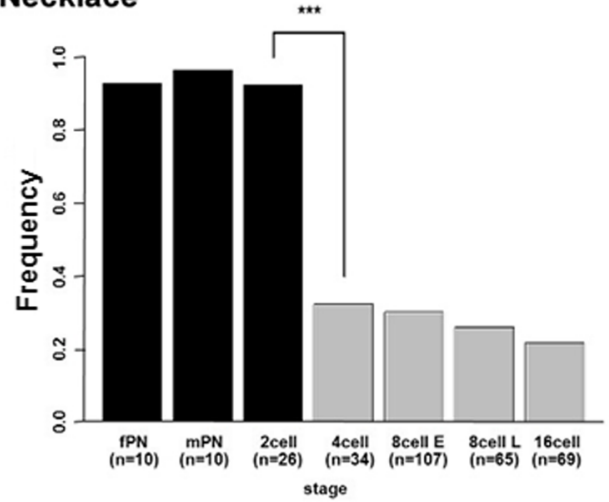

NPBs

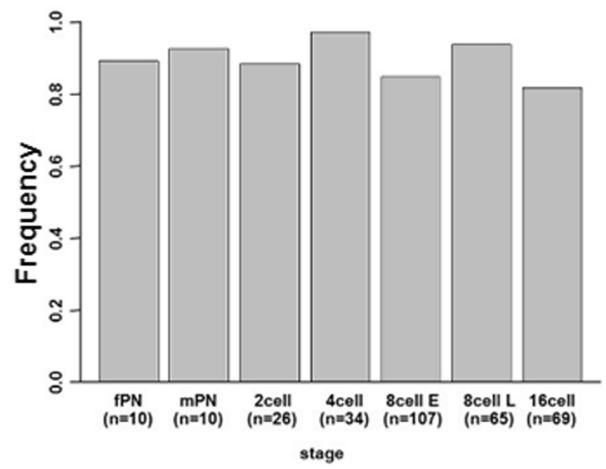

Fig. 2 Spatial organization of Rsat I/II sequences during preimplantation development in the rabbit. a-c, $\mathbf{c}^{\prime}$ Single confocal section of representative images (a-c) with Rsat I (green), Rsat II (red), and DNA (gray) labeling as well as the corresponding $3 \mathrm{D}$ reconstruction $\left(\mathbf{c}^{\prime}\right)$ obtained using Amira software. These images illustrate the four parameters used to analyze the distribution of Rsat I/Rsat II FISH signals in the nucleus of rabbit embryos: (1) necklace (fine arrow in a), (2) aggregate (arrow in b), (3) NPBs (asterisks in a, b), and (4) peripheral (arrowheads in c, $\mathbf{c}^{\prime}$ ). Scale $\mathrm{bar}=2 \mu \mathrm{m}$. lower panel Histograms corresponding to the frequencies of

envelope (named "peripheral"; arrowhead in Fig. 2c, c'). We quantified them in terms of their presence (1) or absence ( 0 ) at each stage. These parameters were not mutually exclusive.

As shown in Fig. 2, the pearl necklace organization of Rsat I and Rsat II sequences was characteristic of the 1- and 2-cell stages (Fig. 2, necklace). The percentage of nuclei with this structure exceeded $90 \%$ at these stages, then decreased significantly $\left(p<10^{-5}\right)$ and rapidly at later stages to reach only $\sim 20 \%$ at the 16-cell stage. Conversely, the organization of the signal in aggregates (Fig. 2, aggregate) was little present at the 1-cell stage and then increased significantly after the 2-
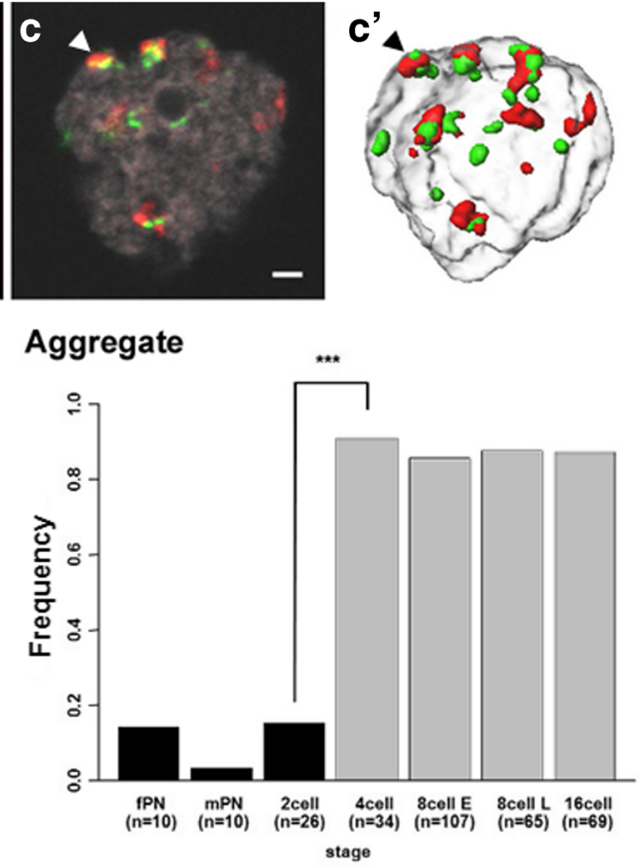

Peripheral

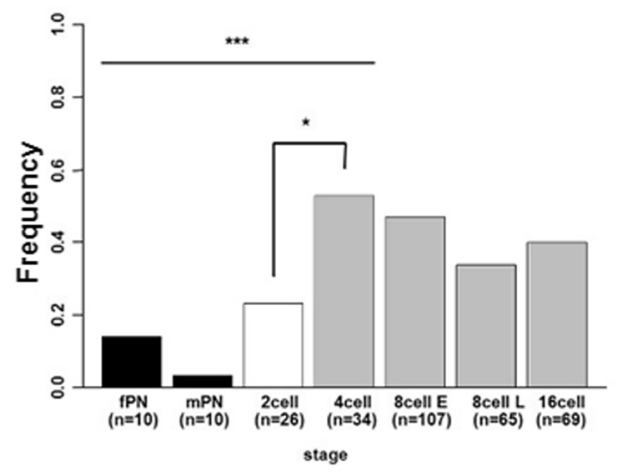

these four parameters at each stage of early development in the rabbit (1to 16-cell stages). At the 1-cell stage, female and male pronuclei (mPN and $\mathrm{fPN}$, respectively) are considered separately. The difference in frequencies between 2- and 4-cell stages for the necklace and aggregate parameters are highly significant $\left(* * * p<10^{-5}\right)$. NPB parameter frequencies are homogenous throughout early development. Differences in the frequencies of the peripheral parameter are significant between $\mathrm{PPN}-\mathrm{mPN}$ and the 4-cell stage $(* * * p<0.005)$ and less significant between the 2 - and 4-cell stages $(* p<0.1)$

cell stage $\left(p<10^{-7}\right)$. Indeed, only $\sim 15 \%$ of the nuclei had this configuration at the 2-cell stage, whereas this percentage reached more than $85 \%$ during subsequent stages. In fact, these two necklace and aggregate parameters displayed opposite behaviors and their frequencies switched significantly at the 4-cell stage, as shown in Fig. 2. The "NPB" parameter (Fig. 2, NPBs) did not vary during this period of embryonic development and a high percentage of the nuclei (85-97\%) presented Rsat sequences associated with NPBs (arrows in Fig. S1c). Finally, the percentage of nuclei displaying an RsatI/RsatII distribution at the nuclear periphery (Fig. 2, 
peripheral) was very low $(\sim 14 \%)$ at the 1- and 2-cell stages when compared to later stages, the difference being significant $(p=0.0223)$. Moreover, at the 1-cell stage, $\mathrm{fPN}$ displayed a higher percentage signal $(14.3 \%)$ at the periphery than $\mathrm{mPN}$ $(3.6 \%)$, of minor significance $(p=0.0616)$. This percentage reached a maximum $(\sim 53 \%)$ at the 4 -cell stage, and then decreased slightly during subsequent stages when fewer than $46 \%$ of the nuclei displayed this distribution (no significant difference).

\section{Spatial analyses of Rsat I/Rsat II sequence distribution during early development}

The visual analysis data suggested that Rsat sequences were not randomly distributed but mainly located in the nuclear center, except at the 4-cell stage. As well as being more peripheral, Rsat signals also appeared to be restricted to one part of the nucleus, i.e., polarized. To test these hypotheses, we segmented 3D images of nuclei from post-zygotic embryonic stages (as described in the "Material and methods" section) to measure several nuclear shape parameters (volume, area, etc.).

From these data, we observed that nuclear volume decreased progressively (Fig. S3a) from the 2-cell $\left(2794.47 \mu \mathrm{m}^{3} \pm\right.$ $1136.91 ; n=24)$ through the 16-cell stage $\left(1152.17 \mu \mathrm{m}^{3} \pm\right.$ $406.79 ; n=93$ ) as had previously been described during early embryonic development in the mouse (Aguirre-Lavin et al. 2012). Similarly, we segmented the Rsat I/Rsat II fluorescent signals that enabled a quantitative analysis of number of spots per nucleus. We then calculated the mean numbers of spots per nucleus and per stage (Table 1) and compared them to the number of spots expected as determined in metaphase (Fig. 1a), i.e., 24 spots for Rsat I and 12 spots for Rsat II. We also measured the total volume occupied by Rsat I and Rsat II FISH spots per nucleus (Fig. S3b, c) and calculated the mean volume of each spot for Rsat I and Rsat II FISH signals, respectively (Fig. S3d, e). These last measures (Fig. S3d, e) showed that Rsat II spots mean volume is always higher than Rsat I spots, which could be explained by a higher number of repeats (Ékes et al. 2004).

The mean number of Rsat I/Rsat II spots was statistically higher from that expected at the 2-cell stage but not at the 4cell stage (Table 1). This could be due to the decondensed status of Rsat signals at early stages (Fig. 1), allowing the detection of signal doublets upon replication or leading to artefactual signal segmentation. Indeed, there was an overall decrease in the mean number of Rsat I/Rsat II spots from the 2- to 4-cell stage (Fig. 3a, b) that was highly significant. The total volume of both Rsat signals decreased from the 2- to 4cell stage (Fig. S3b, c), suggesting a compaction of these sequences from the 4-cell stage.

At later stages, we observed fewer Rsat I/Rsat II spots than expected from the 8- to 16-cell stages (Table 1) and the reduction in the number of Rsat I spots was highly significant between the late 8- and 16-cell stages $(p=0.00108$, Student's $t$ test). This reduction in the number of spots could be explained by aggregation of the Rsat signals. However, while the total volume of both Rsat signals increased slightly until the 16-cell stage (Fig. S3b, c), supporting this hypothesis, the mean spot volumes were constant for Rsat I as well as Rsat II whatever the stage (Fig. S3d, e). Since the volume of the nuclei also decreased during this period, we therefore examined Rsat volumes (I and II) normalized to the nuclear volume (Fig. 3c, d). We observed that this ratio remained constant from the 2- to 8cell stage, independently of the Rsat sequence or the stage analyzed, and increased significantly at the 16-cell stage $\left(p<10^{-11}\right)$. We concluded that Rsat I/Rsat II sequences aggregated from the 8-cell through the 16-cell stages, as illustrated by an increase in spot volume and a reduction in their number.

Next, we decided to determine the radial distribution of the signal using EVF methods. EVF is a normalized measurement of the radial position of the center of an object (see the "Material and methods" section). The EVF value ranged from 0 at the periphery to 1 at the center. EVF was calculated for each Rsat spot per nucleus (Fig. S4), and we observed that Rsat signals (independently of sequences and stages) were mostly detected in the center of the nucleus. In order to compare the results obtained in histogram form, we calculated the maximum algebraic distance (noted $d_{\max }$ ) between the observed EVF distributions of Rsat signals and a theoretical distribution function that followed the uniform law. We then used the Kolmogorov-Smirnov test to compare the distribution of $d_{\max }$ values between two stages and calculate the corresponding $p$ values (Fig. 3e). Statistical analysis (linear model) of the $d_{\max }$ distribution confirmed that all Rsat signals were localized in the center of the nuclei ( $p$ values $<0.005$; Fig. 3e) and showed that there were no significant differences between the distributions of Rsat I and II signals, although the latter were more central than those of Rsat I ( $p$ values $>0.1$; data not shown). Statistical analysis (linear model) of Rsat signal distribution during development indicated a slight tendency to move towards the periphery at the 4-cell stage ( $p$ value $=$ $0.016)$. The Rsat sequences then return to the center of the nuclei at the 8-cell stage ( $p$ value $=0.033$ ).

We then determined whether the spots were polarized in the nuclei by comparing the distances between the center of gravity of the nucleus (called centroid) and that of the Rsat spots. We evaluated whether the distribution of this distance differed significantly from a theoretical distribution and calculated a $p$ value (Fig. 3f). The greater the distance is (or the lower the $p$ value is), the more polarized the signal is. As had previously been shown, there was no significant difference between Rsat I and II. All stages displayed statistically significant polarization ( $p$ values $<0.05$ ) except the 16 -cell stage. This polarization changed during development: it increased between the 2and 4-cell stages ( $p$ value $=0.01$ ) and then decreased between the 8 - and 16-cell stages $\left(p<10^{-12}\right)$. This quantitative analysis thus confirmed that the 4-cell (as observed in Fig. S2) and 8- 
Table 1 Analysis of the number of Rsat I/II spots during preimplantation development in the rabbit

\begin{tabular}{|c|c|c|c|c|c|}
\hline \multirow[t]{2}{*}{ Stage } & \multirow[t]{2}{*}{ No. of nuclei studied } & \multicolumn{2}{|l|}{ Rsat I } & \multicolumn{2}{|l|}{ Rsat II } \\
\hline & & Mean \pm SD & $p$ value & Mean \pm SD & $p$ value \\
\hline 2-cell (27 hpc) & 24 & $26.17 \pm 5.08$ & 0.04788 & $16.96 \pm 6.10$ & 0.000592 \\
\hline 4-cell (34 hpc) & 37 & $21.78 \pm 6.57$ & 0.04767 & $11.57 \pm 3.34$ & 0.4358 \\
\hline Early 8-cell (42 hpc) & 104 & $20.96 \pm 4.86$ & $5.392 \mathrm{e}-09$ & $10.04 \pm 2.89$ & $3.878 \mathrm{e}-10$ \\
\hline Late 8-cell (49 hpc) & 72 & $20.30 \pm 3.44$ & $1.49 \mathrm{e}-13$ & $9.60 \pm 2.41$ & $2.241 \mathrm{e}-12$ \\
\hline 16-cell (58 hpc) & 93 & $18.30 \pm 3.56$ & $2.2 \mathrm{e}-16$ & $9.18 \pm 2.78$ & $7.552 \mathrm{e}^{-16}$ \\
\hline
\end{tabular}

We performed Student's $t$ test to compare the theoretical number of Rsat I spots $(\mu 0=24)$ or Rsat II spots $(\mu 0=$ 12) found on metaphase with the observed numbers of Rsat I or Rsat II spots counted automatically in the segmented nuclei of rabbit embryos at several stages. The $p$ value in italic correspond to an alpha risk higher than 0.05 (the risk of rejecting the Null hypothesis when in fact it is true) cell stages displayed a more polarized state than all the other stages.

\section{Heterochromatin and NPB interactions during early development in the rabbit}

As previously noted, at least one NPB was located close to the Rsat sequences at all stages. Therefore, in order to clarify a possible link between NPB and Rsat sequence organization, we counted the total number of NPBs and the number of NPBs associated with Rsat sequences. We observed a pronounced decrease in the total number of NPBs from the 2cell through the 16-cell stage (Fig. 4a). We found that the number of NPBs with (at least one) Rsat FISH signal at its periphery (asterisk in Fig. 1b, arrows in Fig. S1c, and arrowheads in Fig. 4e) decreased from the 2-cell (5.17 \pm 2.96) through the 4-cell stage (3.18 \pm 1.68$)$ (Fig. 4b). However, the number of NPBs with signals divided by the total number of NPBs increased during development (gray line in Fig. 4f), suggesting that NPBs without Rsat signals were disappearing.

Rsat I and II probes did not label all the chromosomes, so we also analyzed the distribution of HP1 $\beta$ and CENPs at the same stages. In rabbit embryos, HP $1 \beta$ foci appeared and started to associate with CENP dots at the 4-cell stage. The clustering of HP $1 \beta$ associated with CENP dots reached a maximum at the 8-cell stage (Fig. S5; Yang et al. 2013). We evaluated the number of NPBs associated with CENP dots at their periphery (asterisk in Fig. S5 and green arrows in Fig. 4e) in 1-cell through 16-cell stage embryos. As observed on the 3D-FISH images, the total number of NPBs decreased significantly from the 2-cell through the 16-cell stages ( $p=4.511 \mathrm{e}$ -08 ) (Fig. 4c). The number of NPBs associated with CENP dots fell from a mean number of $7.14( \pm 2.80)$ at the 1-/2-cell stages to a mean number of $2.28( \pm 1.62)$ at the 16-cell stage (Fig. 4d). As described for Rsat sequences, the normalized mean number of NPBs associated with CENP dots increased throughout development (Fig. 4f, black line).
The mean number of NPBs per stage analyzed using the two different signals (Rsat FISH and CENP) differed significantly at the 4-, 8-, and 16-cell stages between the two types of image, but followed the same trend. We did not observed any significant difference between the slopes of the two linear curves ( $p=0.985$; gray and black lines in Fig. $4 \mathrm{f}$ ) that represent the number of NPBs associated with Rsat FISH signals and the number of NPBs associated with CENP signals, both normalized to the total number of NPBs.

Overall, NPB interactions with heterochromatin regions appeared to change in shape during very early development in the rabbit. The Rsat sequences were organized in pearl necklace structures wrapping the NPBs during the first two developmental stages (Fig. 1 and Fig. S1c), and then formed smaller clusters during subsequent stages (Figs. 1 and 2). Although still interacting with NPBs up to the 16-cell stage, the surface of interaction between these sequences and the NPBs seems to decrease.

To further investigate the behavior of these pericentromeric regions, we performed immunostaining with two classical heterochromatin histone marks (H3K9me3 and H4K20me3) concomitantly with HP1 $\beta$ on whole-mount embryos from the 1cell through the 16-cell stages (Fig. S6 and Fig. 5).

As expected, H3K9me3 staining specifically labeled the female chromatin (fPN) at the 1-cell stage (Reis e Silva et al. 2011; Fig. S6, upper panel) and was restricted to one side of the nucleus at the 2-cell stage (Fig. 5a). H3K9me3 surrounded NPBs at the 2- and 4-cell stages (Fig. 5a, arrows) and colocalized with HP1 $\beta$ clusters at the 8- and 16-cell stages (Fig. 5a, arrowheads). Similarly, we only found H4K20me3 signal in the fPN at the 1-cell stage (Fig. S6, lower panel). Then, the signal was located in one part of the nucleus at the 2cell and was even brighter around the NPBs at the 4-cell stage (Fig. 5b, arrow). From the 8-cell through the 16-cell stage, all the nuclei displayed H4K20me3 patches which co-localized partially with HP1 clusters (Fig. 5b, arrowhead). Taken together, these data suggest that epigenetic modifications affect these regions during the very early stages of development. 

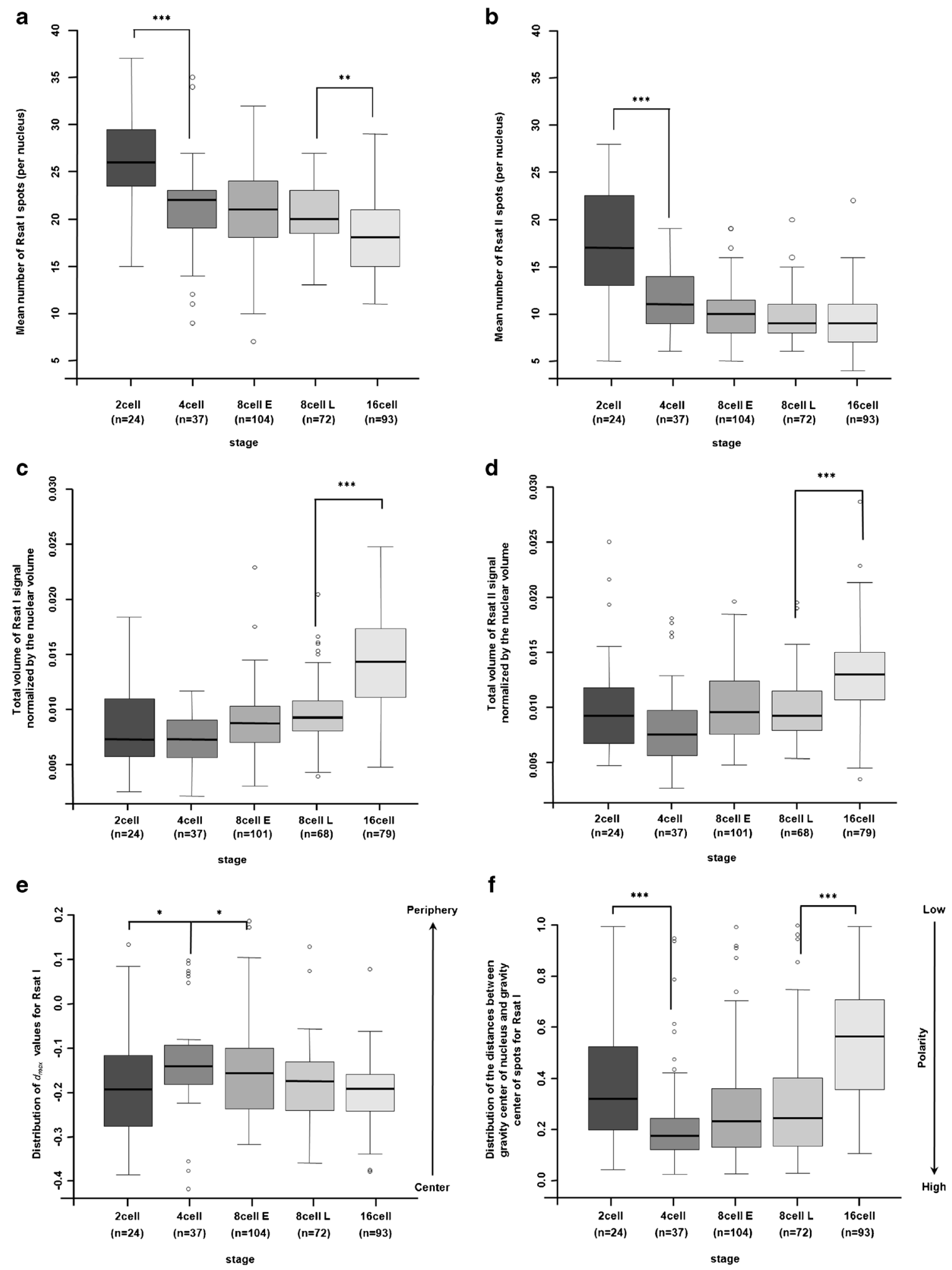

Fig. 3 Quantitative automated analysis of Rsat I/Rsat II FISH signals in preimplantation rabbit embryos. Box plots indicate (per nucleus and per stage) the mean number of Rsat I (a) and Rsat II (b) spots and the fraction of the nuclear volume occupied by Rsat I/Rsat II FISH signals (c, d). Box plots (e) represent the maximum distance $\left(d_{\max }\right)$ values between a theoretical uniform distribution and the observed distribution of EVF in nuclei. $d_{\max }$ values vary between -1 and 1 , with positive values indicating a bias towards a more peripheral signal, and negative values

a more central one. Box plots (f) represent the distribution of distances between the centers of gravity of the nucleus and Rsat spots (values range from 0 to 1 ). This distribution allows us to evaluate the degree of polarity (high vs. low) of Rsat (I or II) signals in the nuclei at each developmental stage. The number of nuclei analyzed at each stage is indicated in brackets under the name of the stage. Significant differences in mean values between stages are indicated by asterisks $\left(* * * p<10^{-5}, * * p<0.001\right.$, and $* p<0.05)$ 


\section{Discussion}

During this study, we examined the spatial and temporal distribution of pericentromeric heterochromatin regions in rabbit embryos labeled with fluorescence probes specific to Rsat I and Rsat II sequences over the course of early embryonic development (from the 1- to 16-cell stage), using the 3D image computational analysis of various nuclear parameters (nuclear volume, Rsat volume, NPB number, etc.).

\section{Spatial organization of pericentromeric heterochromatin regions and EGA}

Our results showed that Rsat sequences (i) exhibited a "bead on a string" structure at the 1- and 2-cell stages; (ii) started to compact at the 4-cell stage, i.e., just before EGA; and (iii) aggregated at the 8- and 16-cell stages, i.e., during and after EGA. We also found that independently of the stage, Rsat sequences displayed a central position in the nuclei (although at the 4-cell stage, their location was closer to the periphery). More intriguing was that these sequences were not randomly distributed in the nucleus. Statistical analysis underlined the fact that Rsat sequences were polarized and significantly located in one part of the nuclei at the 4-cell and early 8-cell stages. These results agreed with the data previously obtained by our laboratory using a similar approach on early-stage mouse embryos (Aguirre-Lavin et al. 2012). These changes to the spatial organization of Rsat sequences at the 4-cell stage in the rabbit may be linked to the context of major EGA at the 8-cell stage that might require heterochromatin reshaping before that time. Indeed, in the mouse, decompaction of the pericentromeric regions occurs when minor transcription is activated (1-cell stage) and ends with EGA (at the 2-/4-cell stages). Interestingly, other studies (Probst et al. 2010; Casanova et al. 2013) demonstrated the importance of pericentromeric sequence transcription at the end of the zygotic stage and during the 2-cell stage which enables developmental progression beyond the 2-cell stage. They also showed that major satellite transcripts are required for the reorganization of pericentromeric heterochromatin regions in chromocenters (Probst et al. 2010). Given these findings in the mouse, it might be interesting to test whether Rsat sequences are transcribed during early embryonic stages (before and after EGA) in the rabbit, and whether inhibition of their transcription might be detrimental to further development.

\section{Nuclear volume and NPBs in rabbit embryos}

In a recent study, Popken and colleagues showed that nuclear volume in rabbit embryos decreases from the 2-cell through the blastocyst stages (Popken et al. 2016). We found similar results during our study using different analytical methods. Furthermore, previous studies in mouse (Aguirre-Lavin et al.
2012) and bovine (Popken et al. 2015) embryos had demonstrated a similar reduction in average nuclear volume during early development. These findings allowed us to postulate that this phenomenon is conserved among mammalian species. In addition, Popken et al. (2016) demonstrated a major remodeling of the nuclear envelope during early development in the rabbit. More precisely, they revealed a peak of nuclear membrane invaginations that were positive for lamin B and Nup153 (a nucleoporin that participates in formation of the nuclear pore complex) at the 4-cell stage. They speculated that these invaginations ensure proximity to the cytoplasm for NPBs and might reflect a considerable need for proteins at this particular stage, concomitantly with the first step of nucleologenesis (Baran et al. 1997). Similar to our previous study in the mouse (Aguirre-Lavin et al. 2012), we found that the overall number of NPBs decreased at the 4-cell stage and even more drastically at the 8-cell stage, when rRNA transcription starts (Baran et al. 1997). Our observations also revealed that pericentromeric regions always interacted with NPBs but that these interactions changed in shape over the course of development. Indeed, pericentromeric heterochromatin region sequences reorganized themselves from a pearl necklace distribution surrounding NPBs into a cluster distribution juxtaposed to the NPBs. Thus, even if the pericentromeric heterochromatin regions were still in interaction with NPBs, the amount of interactions appeared to decrease at the 4-cell stage of development. Taken together, these findings tempt us to speculate that important changes occur at the 4-cell stage. These changes may link nucleogenesis and heterochromatin organization, as was already suggested by a recent study in mouse embryos (Fulka and Langerova 2014).

\section{Epigenetic features of heterochromatin in the rabbit}

In this study, we were able to confirm our previous data demonstrating the distribution of HP $1 \beta$ and CENPs during rabbit development in fertilized and cloned embryos (Yang et al. 2013). While HP1 $\beta$ presented a diffuse pattern in the nucleoplasm from the 1- to 2-cell stages, RsatI/II distribution was much more dispersed, as described above. We can therefore assume that there was no correlation between the pattern of HP1 $\beta$ immunostaining and the location of Rsat sequences at these stages. More HP $1 \beta$ foci, or even patches, were observed at the 4-cell stage, but no chromocenter-like structure could be seen in the rabbit embryonic cell nucleus before the 8-cell stage (at the time of EGA). We presume that Rsat sequences may mainly correspond to pericentromeric regions rather than centromeric regions, and that CENPs allow monitoring of the behavior of centromeric regions.

We questioned whether pericentromeric heterochromatin regions in the rabbit followed the same rules as pericentromeric heterochromatin regions in the mouse 


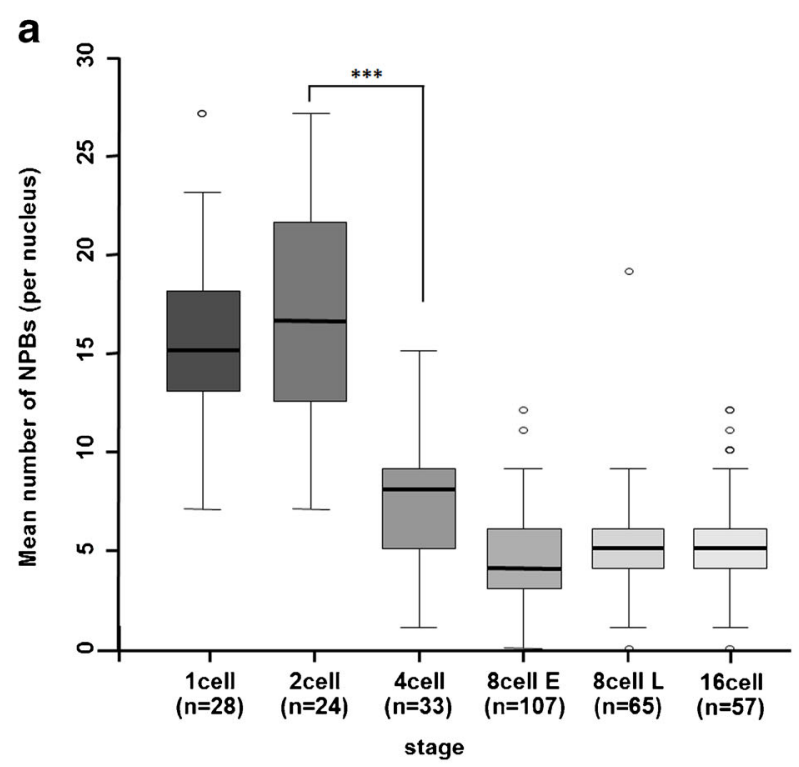

b
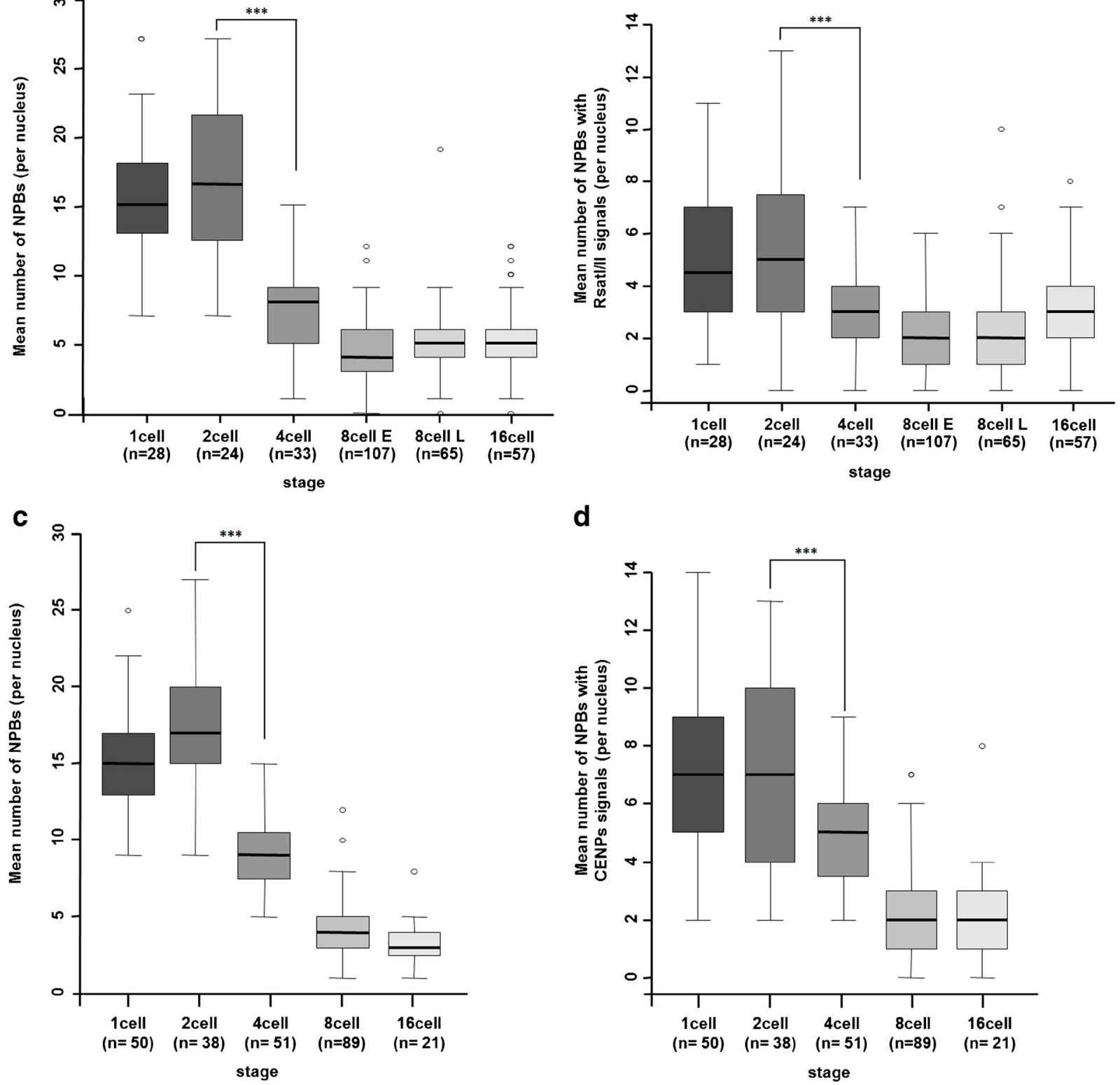

d
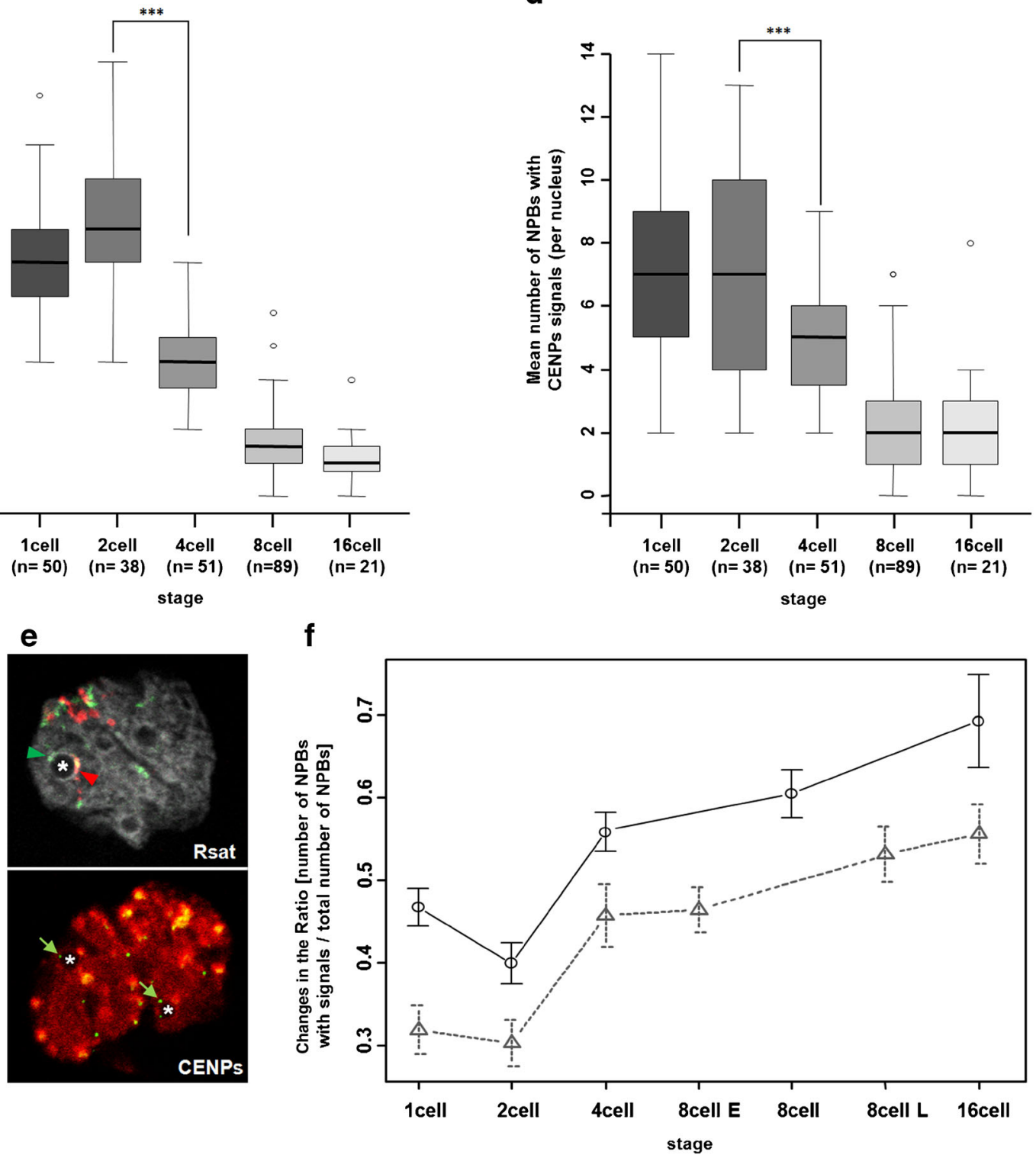
Fig. 4 Quantitative analysis of the number of NBPs and associations with the pericentromeric/centromeric regions in preimplantation rabbit embryos. a, b Box plots indicating the total number of NPBs (a) and the number of NPBs associated with Rsat (I or II or both) FISH signals (b) counted in Rsat 3D images (representative NPBs are indicated with an asterisk in Fig. 1 and an arrow in Fig. S1c). c, d Box plots indicate the total number of NPBs (c) and the number of NPBs associated with CENP immunolabeled signals (d) counted in CENP/HP1 $\beta$ 3D images (Fig. S5). e Single confocal section of representative images of NPBs (indicated with an asterisk) associated with Rsat I (green arrowhead) and Rsat II (red arrowhead), in the upper panel, and associated with CENPs (green arrows), in the lower panel. upper panel Rsat I (green), Rsat II (red), and DNA (gray). lower panel CENPs (green) and HP1 $\beta$ (red). f This figure shows changes in the ratio between the number of NPBs associated with Rsat I/Rsat II signals (dashed line with triangle markers) or CENP signals (solid line with circle markers) and the total number of NPBs during preimplantation development. The number of nuclei analyzed at each stage is indicated in brackets under the name of the stage. Significant differences in mean values between stages are indicated by asterisks $\left(* * * p<10^{-5}\right)$

(Santenard et al. 2010; Beaujean 2014) or bovine (Pichugin et al. 2010). We therefore examined the distribution of H3K9me3 and H4K20me3 (two classic markers of constitutive heterochromatin) from the 1-cell through the 16-cell stage.

As demonstrated in the mouse (Santos et al. 2005) and bovine (Pichugin et al. 2010), we also found that H3K9me3 labeled the maternal genome in rabbit zygotes (Reis e Silva et al. 2011). In the mouse, this mark is particularly enriched at the maternal pericentric heterochromatin (Probst et al. 2007; Puschendorf et al. 2008; Tardat et al. 2015). However, the signal was more dispersed in rabbit embryos, although rings around the NPBs could sometimes be detected (arrow in Fig. $5 \mathrm{a})$. On the other hand, the asymmetry of $\mathrm{H} 3 \mathrm{~K} 9 \mathrm{me} 3$ between the paternal and maternal genomes was clearly detectable up to the 4-cell stage, which is similar to findings in the mouse (Beaujean 2002; Mason et al. 2012) and bovine (Pichugin et al. 2010). Furthermore, as was previously shown in the mouse (Martin et al. 2006a) and bovine (Pichugin et al. 2010), we found that the H3K9me3 signal gradually colocalized with HP1 $\beta$ patches or clusters at the time of EGA.

In mouse and human somatic cells, the tri-methylation on lysine 20 of histone 4 (H4K20me3) is localized primarily at centromeres, pericentromeres, and telomeres (Schotta et al. 2008). The present study is the first that describes H4K20me3 during early development in the rabbit. $\mathrm{H} 4 \mathrm{~K} 20 \mathrm{me} 3$ staining was very similar to $\mathrm{H} 3 \mathrm{~K} 9 \mathrm{me} 3$ staining. As in mouse, this histone mark was found only on the female pronucleus at the 1-cell stage. However, this mark was quite dispersed in the rabbit female pronucleus, while in the mouse, H4K20me3 signal was found only around NPBs (Probst and Almouzni 2008; Eid et al. 2016). After the 1-cell stage, comparison with the mouse is more complicated. We found contradictory data in the literature: some authors (Wongtawan et al. 2011; Eid et al. 2016) could not detect H4K20me3 after a

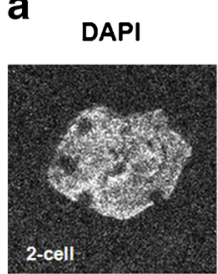

\section{HP1ß}
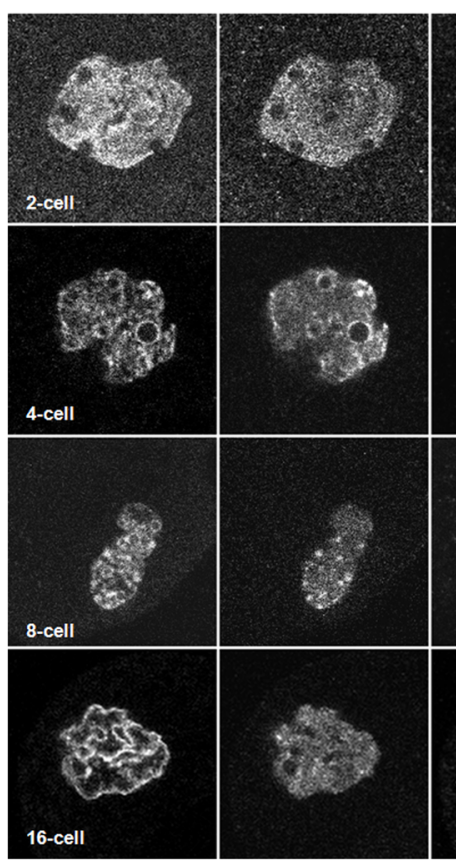

Fig. 5 Spatial localization of H3K9me3 and H4K20me3 during rabbit preimplantation development. Single confocal section of representative images of nuclei from embryos fixed at the 2-cell ( $24 \mathrm{hpc})$, 4-cell (34 hpc), 8-cell (49 hpc), and 16-cell (58 hpc) stages. Scale bar $=5 \mu \mathrm{m}$.

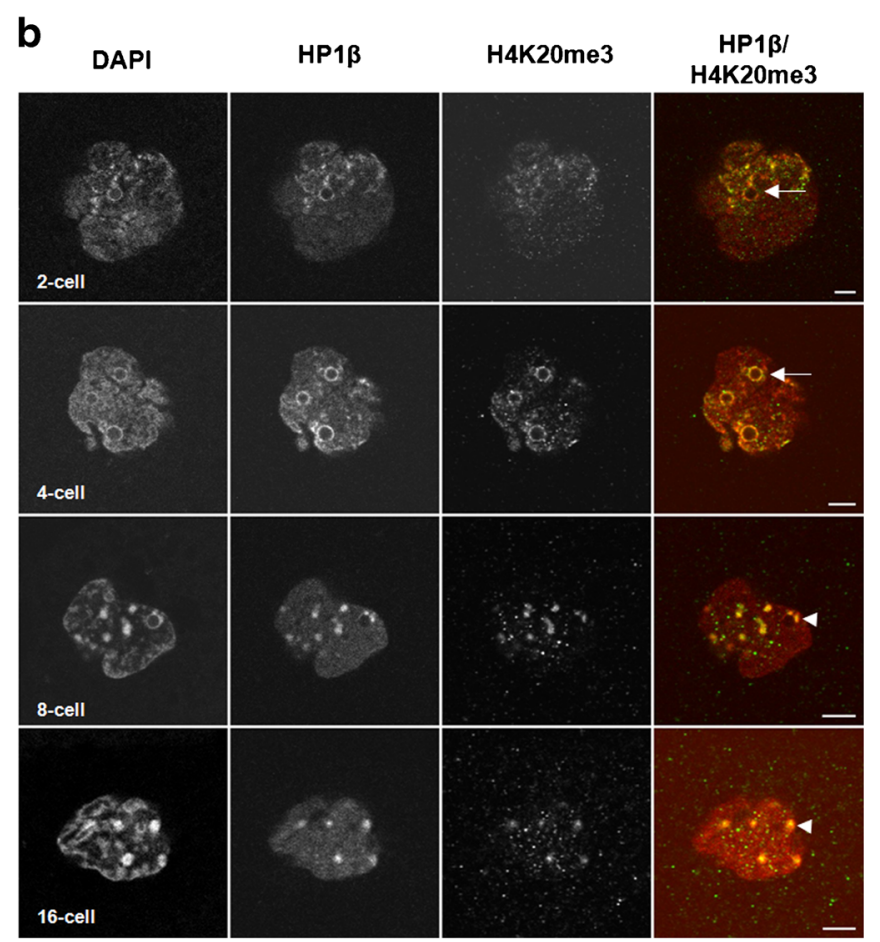

Arrow indicates an accumulation of the stained protein around NPB. Arrowhead indicates an accumulation of the stained protein forming clusters. left panel Immunostaining of H3K9me3 (green) and HP1 $\beta$ (red). right panel Immunostaining of H4K20me3 (green) and HP1 $\beta$ (red) 
the 1-cell stage, whereas others (Puschendorf et al. 2008; Ancelin et al. 2016) have shown, in supplementary data, staining of H4K20me3 in 2-cell mouse embryos. These differences could be due to the antibody used to detect $\mathrm{H} 4 \mathrm{~K} 20 \mathrm{~m} 3$. When we performed immunostaining experiments in rabbit embryos with the same antibodies (Fig. 5b and Fig. S6, lower panel; data not shown), we observed H4K20me3 signal from the 1cell through the 16-cell stages. Interestingly, H4K20me3 condensed and formed clusters partially co-localized with HP $1 \beta$ at the 8-cell stage, the EGA stage in rabbit, thus correlating with the H4K20me3 staining observed on chromocenters in 2cell mouse embryos (Fig. S7; Puschendorf et al. 2008; Ancelin et al. 2016). This pattern could be explained by the fact that H4K20me3 is deposited by SUV4-20H which is recruited by HP $1 \alpha$, and binds to H3K9me3 (Kourmouli et al. 2004; Schotta et al. 2004).

\section{Conclusion}

In conclusion, we have shown that Rsat I and Rsat II sequences change in terms of their localization and compaction between the 2- and 4-cell stages. The radial distribution and polarization of these pericentromeric sequences differ significantly at the 4-cell stage when compared to other stages of early embryonic development. We also observed that the interaction between heterochromatin and NPBs was important at the start of development (2- and 4-cell stages) and was then modified after EGA.

Taken together, these results highlight the importance of the 4-cell stage as a transition point. This now requires further investigation in order to decipher the architectural changes required for proper embryonic genome activation in the rabbit, and to compare them with other species that undergo major genomic activation after several cell cycles (such as humans and bovine).

Acknowledgments We would like to thank Prof. Qi Zhou and Dr. CaiXia Yang from the Institute of Zoology (IOZ), Chinese Academy of Sciences (CAS), for the fruitful discussions at the start of this project. We also thank N. Daniel for the technical assistance with rabbit embryo collection and Claire Boulesteix for the laboratory facilities, as well as the MIMA2 platform and particularly Pierre Adenot and Renaud Fleurot for the access to confocal and apotome microscope facilities.

Funding This project was funding by the EU FP6 ("Clonet" MRTN-CT2006-035468), EU FP7 ("PluriSys," HEALTH-2007-B-223485), the REVIVE Labex (Investissement d'Avenir, ANR-10-LABX-73), and the French Embassy in Beijing (China) which supports our Sino-French collaboration, the "Labiocem" network.

\section{Compliance with ethical standards}

Conflicts of interest The authors report no conflict of interest. Z Liu, K Tar, N Beaujean, V Duranthon, and A Dynnes have received research grants from EU FP7 ("PluriSys," HEALTH-2007-B-223485). K Tar journey was founded by EU FP6 ("Clonet” MRTN-CT-2006-035468). Z Liu,
$\mathrm{N}$ Beaujean, and A Bonnet-Garnier were supported by the French embassy in Beijing (China). N Beaujean, V Duranthon, M Chebrout, N Peynot, T Aguirre-Lavin, and A Bonnet-Garnier are funded by the REVIVE Labex (Investissement d'Avenir, ANR-10-LABX-73).

Ethical approval All applicable international, national, and/or institutional guidelines for the care and use of animals were followed. This article does not contain any studies with human participants performed by any of the authors.

Open Access This article is distributed under the terms of the Creative Commons Attribution 4.0 International License (http:// creativecommons.org/licenses/by/4.0/), which permits unrestricted use, distribution, and reproduction in any medium, provided you give appropriate credit to the original author(s) and the source, provide a link to the Creative Commons license, and indicate if changes were made.

\section{References}

Aguirre-Lavin T, Adenot P, Bonnet-Garnier A, Lehmann G, Fleurot R, Boulesteix C, Debey P, Beaujean N (2012) 3D-FISH analysis of embryonic nuclei in mouse highlights several abrupt changes of nuclear organization during preimplantation development. BMC Dev Biol 12:30. https://doi.org/10.1186/1471-213X-12-30

Ancelin K, Syx L, Borensztein M, Ranisavljevic N, Vassilev I, BriseñoRoa L, Liu T, Metzger E, Servant N, Barillot E, Chen CJ, Schüle R, Heard E (2016) Maternal LSD1/KDM1A is an essential regulator of chromatin and transcription landscapes during zygotic genome activation. Elife 5:e08851. https://doi.org/10.7554/eLife.08851

Andrey P, Kiêu K, Kress C, Lehmann G, Tirichine L, Liu Z, Biot E, Adenot PG, Hue-Beauvais C, Houba-Hérin N, Duranthon V, Devinoy E, Beaujean N, Gaudin V, Maurin Y, Debey P (2010) Statistical analysis of 3D images detects regular spatial distributions of centromeres and chromocenters in animal and plant nuclei. PLoS Comput Biol 6:e1000853. https://doi.org/10.1371/journal.pcbi. 1000853

Ballester M, Kress C, Hue-Beauvais C, Kiêu K, Lehmann G, Adenot P, Devinoy E (2008) The nuclear localization of WAP and CSN genes is modified by lactogenic hormones in $\mathrm{HC} 11$ cells. J Cell Biochem 105:262-270. https://doi.org/10.1002/jcb.21823

Baran V, Mercier Y, Renard J-P, Fléchon J-E (1997) Nucleolar substructures of rabbit cleaving embryos: an immunocytochemical study. Mol Reprod Dev 48:34-44. https://doi.org/10.1002/(SICI)10982795(199709)48:1<34::AID-MRD5>3.0.CO;2-Q

Beaujean N (2002) Fundamental features of chromatin structure. Cloning Stem Cells 4:355-361

Beaujean N (2014) Histone post-translational modifications in preimplantation mouse embryos and their role in nuclear architecture. Mol Reprod Dev 81:100-112. https://doi.org/10.1002/mrd.22268

Bickmore WA, van Steensel B (2013) Genome architecture: domain organization of interphase chromosomes. Cell 152:1270-1284. https://doi.org/10.1016/j.cell.2013.02.001

Borsos M, Torres-Padilla M-E (2016) Building up the nucleus: nuclear organization in the establishment of totipotency and pluripotency during mammalian development. Genes Dev 30:611-621. https:// doi.org/10.1101/gad.273805.115

Boyle S, Gilchrist S, Bridger JM, Mahy N, Ellis J, Bickmore WA (2001) The spatial organization of human chromosomes within the nuclei of normal and emerin-mutant cells. Hum Mol Genet 10:211-219

Braude P, Bolton V, Moore S (1988) Human gene expression first occurs between the four- and eight-cell stages of preimplantation development. Nature 332(6163):459-461 
Brero A, Hao R, Schieker M, Wierer M, Wolf E, Cremer T, Zakhartchenko V (2009) Reprogramming of active and repressive histone modifications following nuclear transfer with rabbit mesenchymal stem cells and adult fibroblasts. Cloning Stem Cells 11(2): 319-329. https://doi.org/10.1089/clo.2008.0083

Brunet-Simon A, Henrion G, Renard JP, Duranthon V (2001) Onset of zygotic transcription and maternal transcript legacy in the rabbit embryo. Mol Reprod Dev 58(2):127-136

Camous S, Heyman Y, Meziou W, Menezo Y (1984) Cleavage beyond the block stage and survival after transfer of early bovine embryos cultured with trophoblastic vesicles. J Reprod Fertil 72(2):479-485

Camous S, Kopecný V, Fléchon JE (1986) Autoradiographic detection of the earliest stage of $[3 \mathrm{H}]$-uridine incorporation into the cow embryo. Biol Cell 58(3):195-200

Casanova M, Pasternak M, El Marjou F, Le Baccon P, Probst AV, Almouzni G (2013) Heterochromatin reorganization during early mouse development requires a single-stranded noncoding transcript. Cell Rep 4:1156-1167. https://doi.org/10.1016/j.celrep.2013.08.015

Chambeyron S, Bickmore WA (2004) Chromatin decondensation and nuclear reorganization of the HoxB locus upon induction of transcription. Genes Dev 18:1119-1130

Chandra T, Narita M (2013) High-order chromatin structure and the epigenome in SAHFs. Nucleus 4:23-28. https://doi.org/10.4161/nucl. 23189

Cheutin T, McNairn AJ, Jenuwein T, Gilbert DM, Singh PB, Misteli T (2003) Maintenance of stable heterochromatin domains by dynamic HP1 binding. Science 299(5607):721-725

Cremer T, Cremer M (2010) Chromosome territories. Cold Spring Harb Perspect Biol 2:a003889-a003889. https://doi.org/10.1101/ cshperspect.a003889

Croft JA, Bridger JM, Boyle S, Perry P, Teague P, Bickmore WA (1999) Differences in the localization and morphology of chromosomes in the human nucleus. J Cell Biol 145:1119-1131

Dekker J, Heard E (2015) Structural and functional diversity of topologically associating domains. FEBS Lett 589:2877-2884. https://doi. org/10.1016/j.febslet.2015.08.044

Dundr M (2012) Nuclear bodies: multifunctional companions of the genome. Curr Opin Cell Biol 24:415-422. https://doi.org/10.1016/j. ceb.2012.03.010

Dundr M, Misteli T (2010) Biogenesis of nuclear bodies. Cold Spring Harb Perspect Biol 2:a000711-a000711. https://doi.org/10.1101/ cshperspect.a000711

Eid A, Rodriguez-Terrones D, Burton A, Torres-Padilla M-E (2016) SUV4-20 activity in the preimplantation mouse embryo controls timely replication. Genes Dev 30:2513-2526. https://doi.org/10. 1101/gad.288969.116

Ékes C, Csonka E, Hadlaczky G, Cserpán I (2004) Isolation, cloning and characterization of two major satellite DNA families of rabbit (Oryctolagus cuniculus). Gene 343:271-279. https://doi.org/10. 1016/j.gene.2004.09.029

Fulka H, Aoki F (2016) Nucleolus precursor bodies and ribosome biogenesis in early mammalian embryos: old theories and new discoveries1. Biol Reprod 94:143. https://doi.org/10.1095/biolreprod.115. 136093

Fulka H, Langerova A (2014) The maternal nucleolus plays a key role in centromere satellite maintenance during the oocyte to embryo transition. Development 141:1694-1704. https://doi.org/10.1242/dev. 105940

Fulka H, St John JC, Fulka J, Hozák P (2008) Chromatin in early mammalian embryos: achieving the pluripotent state. Differentiation 76(1):3-14

Graf A, Krebs S, Zakhartchenko V, Schwalb B, Blum H, Wolf E (2014) Fine mapping of genome activation in bovine embryos by RNA sequencing. Proc Natl Acad Sci 111:4139-4144. https://doi.org/10. 1073/pnas.1321569111
Guenatri M, Bailly D, Maison C, Almouzni G (2004) Mouse centric and pericentric satellite repeats form distinct functional heterochromatin. J Cell Biol 166:493-505. https://doi.org/10.1083/jcb.200403109

Haaf T, Schmid M (1991) Chromosome topology in mammalian interphase nuclei. Exp Cell Res 192(2):325-332

Hübner MR, Spector DL (2010) Chromatin dynamics. Annu Rev Biophys 39:471-489. https://doi.org/10.1146/annurev.biophys. 093008.131348

Jachowicz JW, Santenard A, Bender A, Muller J, Torres-Padilla M-E (2013) Heterochromatin establishment at pericentromeres depends on nuclear position. Genes Dev 27:2427-2432. https://doi.org/10. $1101 /$ gad.224550.113

Joffe B, Leonhardt H, Solovei I (2010) Differentiation and large scale spatial organization of the genome. Curr Opin Genet Dev 20:562 569. https://doi.org/10.1016/j.gde.2010.05.009

Kittler J, Illingworth J, Föglien J (1985) Threshold selection based on a simple image statistic. Comput Vis Graphics Image Process 30:125147

Koehler D, Zakhartchenko V, Froenicke L, Stone G, Stanyon R, Wolf E, Cremer T, Brero A (2009) Changes of higher order chromatin arrangements during major genome activation in bovine preimplantation embryos. Exp Cell Res 315:2053-2063. https://doi.org/10. 1016/j.yexcr.2009.02.016

Koné MC, Fleurot R, Chebrout M, Debey P, Beaujean N, Bonnet-Garnier A (2016) Three-dimensional distribution of UBF and Nopp140 in relationship to ribosomal DNA transcription during mouse preimplantation development. Biol Reprod 94:95. https://doi.org/10.1095/ biolreprod.115.136366

Kourmouli N, Jeppesen P, Mahadevhaiah S, Burgoyne P, Wu R, Gilbert DM, Bongiorni S, Prantera G, Fanti L, Pimpinelli S, Shi W, Fundele R, Singh PB (2004) Heterochromatin and tri-methylated lysine 20 of histone H4 in animals. J Cell Sci 117:2491-2501. https://doi.org/10. $1242 /$ jcs. 01238

Kyogoku H, Fulka J, Wakayama T, Miyano T (2014) De novo formation of nucleoli in developing mouse embryos originating from enucleolated zygotes. Development 141:2255-2259. https://doi. org $/ 10.1242 /$ dev. 106948

Lanctot C, Cheutin T, Cremer M, Cavalli G, Cremer T (2007) Dynamic genome architecture in the nuclear space: regulation of gene expression in three dimensions. Nat Rev Genet 8:104-115. https://doi.org/ $10.1038 / \mathrm{nrg} 2041$

Lavrentyeva E, Shishova K, Kagarlitsky G, Zatsepina O (2015) Localisation of RNAs and proteins in nucleolar precursor bodies of early mouse embryos. Reprod Fertil Dev 29(3):509-520. https://doi.org/10.1071/RD15200

Lehmann G, Pincus Z, Regrain B (2006) WrapITK: enhanced languages support for the insight toolkit. The Insight Journal, January-June. URL: http://hdl.handle.net/1926/188

Lehnertz B, Ueda Y, Derijck AA, Braunschweig U, Perez-Burgos L, Kubicek S, Chen T, Li E, Jenuwein T, Peters AH (2003) Suv39hmediated histone $\mathrm{H} 3$ lysine 9 methylation directs DNA methylation to major satellite repeats at pericentric heterochromatin. Curr Biol 13(14):1192-1200

Maalouf WE, Liu Z, Brochard V, Renard J-P, Debey P, Beaujean N, Zink D (2009) Trichostatin a treatment of cloned mouse embryos improves constitutive heterochromatin remodeling as well as developmental potential to term. BMC Dev Biol 9:11. https://doi.org/10. 1186/1471-213X-9-11

Maison C, Almouzni G (2004) HP1 and the dynamics of heterochromatin maintenance. Nat Rev Mol Cell Biol 5:296-305. https://doi.org/10. $1038 / \mathrm{nrm} 1355$

Manes C (1973) The participation of the embryonic genome during early cleavage in the rabbit. Dev Biol 32(2):453-459

Martin C, Beaujean N, Brochard V, Audouard C, Zink D, Debey P (2006a) Genome restructuring in mouse embryos during reprogramming and early development. Dev Biol 292:317-332 
Martin C, Brochard V, Migné C, Zink D, Debey P, Beaujean N (2006b) Architectural reorganization of the nuclei upon transfer into oocytes accompanies genome reprogramming. Mol Reprod Dev 73:11021111. https://doi.org/10.1002/mrd.20506

Maslova A, Zlotina A, Kosyakova N, Sidorova M, Krasikova A (2015) Three-dimensional architecture of tandem repeats in chicken interphase nucleus. Chromosom Res 23:625-639. https://doi.org/10. 1007/s10577-015-9485-5

Mason K, Liu Z, Aguirre-Lavin T, Beaujean N (2012) Chromatin and epigenetic modifications during early mammalian development. Anim Reprod Sci 134:45-55. https://doi.org/10.1016/j.anireprosci. 2012.08.010

Memili E, First NL (1998) Developmental changes in RNA polymerase II in bovine oocytes, early embryos, and effect of alpha-amanitin on embryo development. Mol Reprod Dev 51(4):381-389

Moore GP (1975) The RNA polymerase activity of the preimplantation mouse embryo. J Embryol Exp Morphol 34(2):291-298

Ogushi S, Saitou M (2010) The nucleolus in the mouse oocyte is required for the early step of both female and male pronucleus organization. J Reprod Dev 56:495-501

Peters AHFM, O'Carroll D, Scherthan H, Mechtler K, Sauer S, Schöfer C, Weipoltshammer K, Pagani M, Lachner M, Kohlmaier A, Opravil S, Doyle M, Sibilia M, Jenuwein T (2001) Loss of the Suv39h histone methyltransferases impairs mammalian heterochromatin and genome stability. Cell 107:323-337. https://doi.org/10. 1016/S0092-8674(01)00542-6

Peters AH, Kubicek S, Mechtler K, O'Sullivan RJ, Derijck AA, PerezBurgos L, Kohlmaier A, Opravil S, Tachibana M, Shinkai Y et al (2003) Partitioning and plasticity of repressive histone methylation states in mammalian chromatin. Mol Cell 12:1577-1589

Pichugin A, Le Bourhis D, Adenot P, Lehmann G, Audouard C, Renard JP, Vignon X, Beaujean N (2010) Dynamics of constitutive heterochromatin: two contrasted kinetics of genome restructuring in early cloned bovine embryos. Reproduction 139:129-137. https://doi.org/ 10.1530/REP-08-0435

Politz JCR, Scalzo D, Groudine M (2013) Something silent this way forms: the functional organization of the repressive nuclear compartment. Annu Rev Cell Dev Biol 29:241-270. https://doi.org/10.1146/ annurev-cellbio-101512-122317

Pombo A, Dillon N (2015) Three-dimensional genome architecture: players and mechanisms. Nat Rev Mol Cell Biol 16:245-257. https://doi.org/10.1038/nrm3965

Popken J, Brero A, Koehler D, Schmid VJ, Strauss A, Wuensch A, Guengoer T, Graf A, Krebs S, Blum H, Zakhartchenko V, Wolf E, Cremer T (2014a) Reprogramming of fibroblast nuclei in cloned bovine embryos involves major structural remodeling with both striking similarities and differences to nuclear phenotypes of in vitro fertilized embryos. Nucleus 5:555-589. https://doi.org/10.4161/ 19491034.2014.979712

Popken J, Koehler D, Brero A, Wuensch A, Guengoer T, Thormeyer T, Wolf E, Cremer T, Zakhartchenko V (2014b) Positional changes of a pluripotency marker gene during structural reorganization of fibroblast nuclei in cloned early bovine embryos. Nucleus 5:542-554. https://doi.org/10.4161/19491034.2014.970107

Popken J, Graf A, Krebs S, Blum H, Schmid VJ, Strauss A, Guengoer T, Zakhartchenko V, Wolf E, Cremer T (2015) Remodeling of the nuclear envelope and lamina during bovine preimplantation development and its functional implications. PLoS One 10:e124619. https://doi.org/10.1371/journal.pone.0124619

Popken J, Schmid VJ, Strauss A et al (2016) Stage-dependent remodeling of the nuclear envelope and lamina during rabbit early embryonic development. J Reprod Dev 62:127-135. https://doi.org/10.1262/ jrd.2015-100

Probst AV, Almouzni G (2008) Pericentric heterochromatin: dynamic organization during early development in mammals.
Differentiation 76:15-23. https://doi.org/10.1111/j.1432-0436. 2007.00220.x

Probst AV, Santos F, Reik W, Almouzni G, Dean W (2007) Structural differences in centromeric heterochromatin are spatially reconciled on fertilisation in the mouse zygote. Chromosoma 116:403-415. https://doi.org/10.1007/s00412-007-0106-8

Probst AV, Okamoto I, Casanova M, El Marjou F, Le Baccon P, Almouzni G (2010) A strand-specific burst in transcription of pericentric satellites is required for chromocenter formation and early mouse development. Dev Cell 19:625-638. https://doi.org/10.1016/j.devcel. 2010.09 .002

Puschendorf M, Terranova R, Boutsma E, Mao X, Isono K, Brykczynska U, Kolb C, Otte AP, Koseki H, Orkin SH, van Lohuizen M, Peters AHFM (2008) PRC1 and Suv39h specify parental asymmetry at constitutive heterochromatin in early mouse embryos. Nat Genet 40:411-420. https://doi.org/10.1038/ng.99

R Development Core Team (2008) R: a language and environment for statistical computing. R Foundation for Statistical Computing, Vienna, Austria. ISBN 3-900051-07-0, URL http://www.R-project.org

Reis e Silva AR, Adenot P, Daniel N, Archilla C, Peynot N, Lucci CM, Beaujean N, Duranthon V (2011) Dynamics of DNA methylation levels in maternal and paternal rabbit genomes after fertilization. Epigenetics 6:987-993. https://doi.org/10.4161/epi.6.8.16073

Salvaing J, Peynot N, Bedhane MN, Veniel S, Pellier E, Boulesteix C, Beaujean N, Daniel N, Duranthon V (2016) Assessment of "onestep" versus "sequential" embryo culture conditions through embryonic genome methylation and hydroxymethylation changes. Hum Reprod 31:2471-2483. https://doi.org/10.1093/humrep/dew214

Santenard A, Ziegler-Birling C, Koch M, Tora L, Bannister AJ, TorresPadilla ME (2010) Heterochromatin formation in the mouse embryo requires critical residues of the histone variant H3.3. Nat Cell Biol 12:853-862. https://doi.org/10.1038/ncb2089

Santos F, Peters AH, Otte AP, Reik W, Dean W (2005) Dynamic chromatin modifications characterise the first cell cycle in mouse embryos. Dev Biol 280:225-236. https://doi.org/10. 1016/j.ydbio.2005.01.025

Sawyer IA, Sturgill D, Sung M-H, Hager GL, Dundr M (2016) Cajal body function in genome organization and transcriptome diversity. BioEssays 38:1197-1208. https://doi.org/10.1002/bies.201600144

Schneider R, Grosschedl R (2007) Dynamics and interplay of nuclear architecture, genome organization, and gene expression. Genes Dev 21:3027-3043. https://doi.org/10.1101/gad.1604607

Schotta G, Lachner M, Sarma K, Ebert A, Sengupta R, Reuter G, Reinberg D, Jenuwein T (2004) A silencing pathway to induce $\mathrm{H} 3-\mathrm{K} 9$ and H4-K20 trimethylation at constitutive heterochromatin. Genes Dev 18:1251-1262. https://doi.org/10.1101/gad.300704

Schotta G, Sengupta R, Kubicek S, Malin S, Kauer M, Callen E, Celeste A, Pagani M, Opravil S, De La Rosa-Velazquez IA, Espejo A, Bedford MT, Nussenzweig A, Busslinger M, Jenuwein T (2008) A chromatin-wide transition to H4K20 monomethylation impairs genome integrity and programmed DNA rearrangements in the mouse. Genes Dev 22:2048-2061. https://doi.org/10.1101/gad.476008

Schultz RM (1993) Regulation of zygotic gene activation in the mouse. BioEssays 15(8):531-538

Schultz GA, Heyner S (1992) Gene expression in pre-implantation mammalian embryos. Mutat Res 296(1-2):17-31. https://doi.org/10. 1016/0165-1110(92)90029-9

Schultz RM, Davis W Jr, Stein P, Svoboda P (1999) Reprogramming of gene expression during preimplantation development. J Exp Zool 285:276-282

Solovei I, Kreysing M, Lanctôt C, Kösem S, Peichl L, Cremer T, Guck J, Joffe B (2009) Nuclear architecture of rod photoreceptor cells adapts to vision in mammalian evolution. Cell 137:356-368. https://doi. org/10.1016/j.cell.2009.01.052 
Tardat M, Albert M, Kunzmann R, Liu Z, Kaustov L, Thierry R, Duan S, Brykczynska U, Arrowsmith CH, Peters AHFM (2015) Cbx2 targets PRC1 to constitutive heterochromatin in mouse zygotes in a parent-of-origin-dependent manner. Mol Cell 58:157-171. https:// doi.org/10.1016/j.molcel.2015.02.013

Telford NA, Watson AJ, Schultz GA (1990) Transition from maternal to embryonic control in early mammalian development: a comparison of several species. Mol Reprod Dev 26(1):90-100

Therizols P, Illingworth RS, Courilleau C, Boyle S, Wood AJ, Bickmore WA (2014) Chromatin decondensation is sufficient to alter nuclear organization in embryonic stem cells. Science 346:1238-1242. https://doi.org/10.1126/science. 1259587

Vissel B, Choo KHA (1989) Mouse major (gamma) satellite DNA is highly conserved and organized into extremely long tandem arrays: implications for recombination between nonhomologous chromosomes. Genomics 5:407-414

Volpi EV, Chevret E, Jones T, Vatcheva R, Williamson J, Beck S, Campbell RD, Goldsworthy M, Powis SH, Ragoussis J et al (2000) Large-scale chromatin organization of the major histocompatibility complex and other regions of human chromosome 6 and its response to interferon in interphase nuclei. J Cell Sci 113:1565-1576
Wongtawan T, Taylor JE, Lawson KA, Wilmut I, Pennings S (2011) Histone H4K20me3 and HP1 are late heterochromatin markers in development, but present in undifferentiated embryonic stem cells. J Cell Sci 124:1878-1890. https://doi.org/10.1242/jcs.080721

Yang CX, Liu Z, Fleurot R, Adenot P, Duranthon V, Vignon X, Zhou Q, Renard JP, Beaujean N (2013) Heterochromatin reprogramming in rabbit embryos after fertilization, intra-, and inter-species SCNT correlates with preimplantation development. Reproduction 145: 149-159. https://doi.org/10.1530/REP-11-0421

Yoo TS, Ackerman MJ, Lorensen WE, Schroeder W, Chalana V, Aylward S, Metaxas D, Whitaker R (2002) Engineering and algorithm design for an image processing API: a technical report on ITK-the insight toolkit. In: Westwood J (ed) Proc. of medicine meets virtual reality. IOS press, Amsterdam, pp 586-592

Zatsepina O, Baly C, Chebrout M, Debey P (2003) The step-wise assembly of a functional nucleolus in preimplantation mouse embryos involves the Cajal (coiled) body. Dev Biol 253:66-83. https://doi. org/10.1006/dbio.2002.0865

Zinner R, Albiez H, Walter J, Peters AHFM, Cremer T, Cremer M (2006) Histone lysine methylation patterns in human cell types are arranged in distinct three-dimensional nuclear zones. Histochem Cell Biol 125:3-19. https://doi.org/10.1007/s00418-005-0049-1 